$\underline{\text { Home }}>>$ International Journal of Logistics Systems and Management

\section{International Journal of Logistics Systems and Management}

(2) This journal also publishes Open Access articles

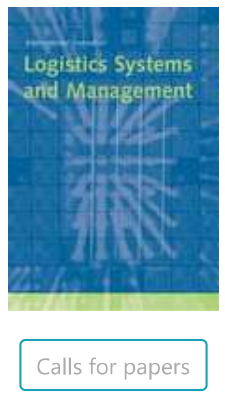

Editor in Chief

Prof. Angappa Gunasekaran

ISSN online

1742-7975

ISSN print

1742-7967

12 issues per year

Subscription price

IJLSM addresses the development of logistics resources, emphasising the implications that logistics strategies and systems have on organisational productivity and competitiveness in global and electronic markets. Globalisation of markets and logistics services is closely related to the success of a company. This perspective indicates the importance of effective logistics systems and their management for organisational effectiveness and competitiveness. The journal intends to provide executives and academics with the state of the art of logistics systems and supply chain management.

\section{About this journal Editorial board Submitting articles}

\section{Topics covered include}

- Logistics enterprise network

- Logistical systems design/development/optimisation

- Performance management, benchmarking

- E-logistics, global logistics

- Logistics information systems, ERP

- Customer relationship management

- Materials handling

- Supply chain management

- Warehouse management

- Purchasing

- Transport management

- Supply chain management information

- Inventory/demand management

- Project/distribution management

- Modelling and analysis

More on this journal...

\section{Browse issues}

Vol. 31

Vol. 30

Vol. 29
Sign up for new issue alerts

Subscribe/buy_articles/issues

View sample issue

Latest issue contents as RSS feed

Forthcoming articles

Journal information in easy_print format (PDF)

Publishing with Inderscience: ethical guidelines (PDF)

View all calls for papers

Recommend to a librarian (PDF).

Feedback to Editor

Find related journals

\section{Keep up-to-date}

$\underline{\text { Our Blog }}$

Follow us on Twitter

f Visit us on Facebook

G. Join us on Google+

$\equiv$ Our Newsletter (subscribe for free)

ה) RSS Feeds

New issue alerts 
Vol. 28

Vol. 27

Vol. 26

More volumes...

\& Get Permission

More on permissions

\section{IJLSM is indexed in:}

- Scopus (Elsevier)

- Academic OneFile (Gale)

- Asian Digital Library.

- cnpliNKer (CNPIEC)

- Expanded Academic ASAP (Gale)

More indexes...

\section{IJLSM is listed in:}

- Australian Business Deans Council Journal Rankings List

- Cabell's Directory of Publishing Oppportunities

More journal lists/directories.. 
$\underline{\text { Home }}>>$ International Journal of Logistics Systems and Management

\section{International Journal of Logistics Systems and Management}

(2) This journal also publishes Open Access articles

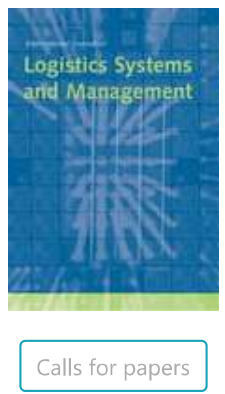

Editor in Chief

Prof. Angappa Gunasekaran

ISSN online

1742-7975

ISSN print

1742-7967

12 issues per year

Subscription price

IJLSM addresses the development of logistics resources, emphasising the implications that logistics strategies and systems have on organisational productivity and competitiveness in global and electronic markets. Globalisation of markets and logistics services is closely related to the success of a company. This perspective indicates the importance of effective logistics systems and their management for organisational effectiveness and competitiveness. The journal intends to provide executives and academics with the state of the art of logistics systems and supply chain management.

\section{About this journal Editorial board Submitting articles}

\section{Editor in Chief}

- Gunasekaran, Angappa, California State University, Bakersfield, USA (an.gunasekaran@gmail.com)

\section{Editorial Board Members}

- Assimakopoulos, Dimitris G., EMLYON Business School, France

- Bagchi, Prabir K., The George Washington University, USA

- Bititci, Umit S., Heriot Watt University, UK

- Camarinha-Matos, Luis M., New University of Lisbon, Portugal

- Christopher, Martin, Cranfield University, UK

- Croom, Simon, University of San Diego, USA

- Fernie, John, Heriot-Watt University, UK

- Goh, Mark, National University of Singapore, Singapore

- Goyal, Suresh, Concordia University, Canada

- Grubbström, Robert W., Linköping Institute of Technology, Sweden

- Gupta, Jatinder (Jeet) N.D., University of Alabama, Huntsville, USA

- Hellebust, Anders, SINTEF Industrial Management, Norway

- Helo, Petri T., University of Vaasa, Finland

- lijima, Masaki, Aichi-Gakuin University, Japan

- Koh, Siau Ching Lenny, University of Sheffield, UK

- Lee, W. B., The Hong Kong Polytechnic University, Hong Kong SAR, China

- Lee, Young Hae, Hanyang University, South Korea

- Lin, Binshan, Louisiana State University in Shreveport, USA

- Macdonald, Stuart, University of Leicester, UK
Sign up for new issue alerts

$\underline{\text { Subscribe/buy_articles/issues }}$

View sample issue

Latest issue contents as RSS feed ה

Forthcoming_articles

Journal information in easy_print format (PDF).

Publishing with Inderscience: ethical guidelines (PDF)

View all calls for papers

Recommend to a librarian (PDF).

Feedback to Editor

Find related journals

\section{Keep up-to-date}

$\underline{\text { Our Blog }}$

Follow us on Twitter

Visit us on Facebook

$\underline{\text { Join us on Google+ }}$

:

St RSS Feeds

New issue alerts 
- Min, Hokey, Bowling Green State University, USA

- Motwani, Jaideep, Grand Valley State University, USA

- Olhager, Jan, Linkoping Institute of Technology, Sweden

- Rajendran, Chandrasekharan, Indian Institute of Technology Madras, India

- Sarkis, Joseph, Worcester Polytechnic Institute, USA

- Singh, Nanua, RGBSI, USA

- Sohal, Amrik, Monash University, Australia

- Taylor, W. Andrew, University of Bradford, UK

- Tsui, Kwok L., Georgia Institute of Technology, USA

- Xie, Min, City University of Hong Kong, Hong Kong SAR, China

- Yusuf, Yahaya, University of Central Lancashire, UK 
International Journal of Logistics Systems and Management > Published issues > 2017 Vol.28 No.2

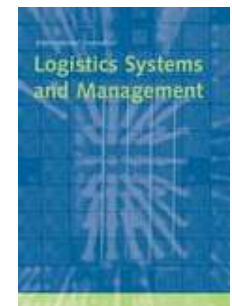

\section{International Journal of Logistics Systems and Management}

\section{Vol.28 No.2}

\section{Pages Title and author(s)}

127-143 Adaptation of simulated annealing to an integrated municipal solid waste location-routing.problem Hossein Asefi; Samsung Lim; Mojtaba Maghrebi DOI: $10.1504 /$ IJLSM.2017.086348

144-163 Configuration and implementation of a daily artificial neural network-based forecasting system using real supermarket data Ilham Slimani; Ilhame El Farissi; Said Achchab DOI: $10.1504 /$ IJLSM.2017.086345

164-179 Supply chain analytics for enhancing the maritime security. Hokey Min; Yong-Kon Lim; Jong-Won Park DOI: $10.1504 /$ IJLSM.2017.086352

180-199 Optimal ordering.policies in a multi-sourcing supply chain with supply and demand disruptions-a CVaR approach Syed Mithun Ali; Koichi Nakade DOI: $10.1504 /$ IJLSM.2017.086354

200-224 Analysis of critical factors influencing the management of green supply chain practice in small and medium enterprises Aparna Choudhary; Sandeep Mondal; Kampan Mukherjee DOI: $\underline{10.1504 / I J L S M .2017 .086356}$

225-252 Multi-objective evolutionary algorithm for a ship routing.problem in maritime logistics collaboration

Eric Wibisono; Phongchai Jittamai DOI: 10.1504/IJLSM.2017.086357

253-266 A study on the effectiveness of inventory management and control system in a milk producer organisation Abhishek S. Rao K.P.; Naresh Nayak DOI: 10.1504/IJLSM.2017.086361

\author{
$\underline{\text { Sign up for new issue alerts }}$ \\ Subscribe/buy_articles/issues \\ View sample issue \\ Latest issue contents as RSS feed \\ Forthcoming articles \\ Journal information in easy_print format \\ (PDF).
}

Publishing with Inderscience: ethical guidelines (PDF)

$\underline{\text { View all calls for papers }}$

Recommend to a librarian (PDF).

Feedback to Editor

Find related journals

\section{Keep up-to-date}

Our Blog

(9) Follow us on Twitter

f Visit us on Facebook

G. Join us on Google+

$: \equiv \underline{\text { Our Newsletter (subscribe for free) }}$

St RSS Feeds

New issue alerts 


\title{
Multi-objective evolutionary algorithm for a ship routing problem in maritime logistics collaboration
}

\author{
Eric Wibisono* \\ Department of Industrial Engineering, \\ Faculty of Engineering, \\ University of Surabaya, \\ Raya Kalirungkut, Surabaya 60293 Indonesia \\ Email: ewibisono@ubaya.ac.id \\ *Corresponding author
}

\section{Phongchai Jittamai}

School of Industrial Engineering,

Institute of Engineering,

Suranaree University of Technology,

111 University Avenue, Muang District,

Nakhon Ratchasima 30000 Thailand

Email: jittamai@sut.ac.th

\begin{abstract}
This paper proposes a multi-objective evolutionary algorithm in maritime logistics collaboration of two liner shipping companies in joint-routing network design. The model is called the ship routing problem and two objectives being minimised are total cost and deviation in fair cost proportion. The method combines NSGA-II and the principles of effective genetic algorithms from the literature, and an example of application with data background from the Indonesian archipelago is demonstrated. Both the method and its application in real-life problems have never been encountered in academic publication, therefore this research has significant contribution and practical values on those fronts. Three dispersal mechanisms are tested with two different mutation probabilities and the results suggest that different rate supports different mechanism. Running times are longer in higher mutation rate, but in general the DV(1) mechanism is faster than both DL mechanisms. Non-dominated solutions are found and translated to joint routings of both carriers.
\end{abstract}

Keywords: multi-objective evolutionary algorithm; ship routing problem; maritime logistics collaboration; routing network design; Indonesian archipelago.

Reference to this paper should be made as follows: Wibisono, E. and Jittamai, P. (2017) 'Multi-objective evolutionary algorithm for a ship routing problem in maritime logistics collaboration', Int. J. Logistics Systems and Management, Vol. 28, No. 2, pp.225-252.

Biographical notes: Eric Wibisono is a faculty member at the University of Surabaya. He obtained his PhD from Suranaree University of Technology, Thailand. His research interests are in the field of transport management and maritime logistics. 
Phongchai Jittamai is an Assistant Professor at the School of Industrial Engineering, Suranaree University of Technology. He obtained his PhD from Texas A\&M University, USA. His research interests are in the field of logistics and supply chain management.

\section{Introduction}

Maritime transportation can be considered as the backbone of world trade and economy. It is estimated that $90 \%$ of global freight are transported via shipping, using different types of vessels across the world's oceans and through man-made waterways (Singapore Logistics Association, 2010). For countries with many islands and long shorelines, the role of maritime logistics is also critical for domestic transportation. The clear advantage of waterborne compared to land-based transportation is its efficiency in dealing with large volume of cargoes. An important segment in maritime logistics is liner shipping that deals with container ships. The fleet capacity of this segment is a mere $13 \%$ of the total world fleet capacity, much lower than that the other segments, e.g., bulk carriers (43\%) and oil tankers (29\%) (UNCTAD, 2014). However, in terms of monetary value, container ships are estimated to carry $52 \%$ of global seaborne trade, equivalent to more than US\$ 4 trillion worth of goods annually (World Shipping Council, 2014). Containers extend the advantage of shipping due to high variety of cargoes that can be handled.

As in any other industry, shipping also faces challenges during economy downturn. For example, the 2008 recession led to a depressed market and caused a heavy imbalance of supply and demand in shipping. As reported in UNCTAD $(2010 ; 2011 ; 2012)$, shipbuilding orders placed prior to 2008 were carried out to construction despite a drastic slump in the world economy and this resulted in excess global capacity in the subsequent years. Shipping companies embark on various efforts to respond such fierce challenges, and collaboration with other companies is one viable path. In liner segment, a common collaboration theme for liner companies is the formation of alliances to enlarge service coverage by taking advantage of the economies of scale.

Collaboration entails certain impacts that should be evaluated. When companies form an alliance, the next strategic decision will be how to assign each company's role and how to fairly divide the works in their operations to serve the aggregate market demands. A number of factors must be determined and investigated in this phase, e.g., how many vessels each company shall contribute to the joint fleet, what is the route of each vessel, what is the resulting total profit/cost and whether or not it is acceptable by the collaborating parties, etc. The answers to these questions are very important and will determine sustainability of partnership. However, studies in this area are still scant in the literature. Most of the studies in maritime logistics collaboration are on the qualitative side and only a few quantitative studies are encountered.

This paper aims to fill that gap in the studies of maritime logistics collaboration. The scope of this paper is collaboration of two liner shipping companies in determining the routing of their fleet. Real-life problems are seldom one-dimensional and single-objective optimisation models are usually built by discharging some factors with assumptions and/or other simplification schemes. A multi-objective approach is therefore used in this study to bring the problem formulation and solutions closer to reality. The first objective is the natural minimisation of total cost. The second objective is a novel formulation of 
fair distribution of the total cost. The rationale behind the second objective is to control the impacts of collaboration so that cost is not minimised in such an unfair proportion, sacrificing the interests of either of the companies involved. A case study using Indonesian archipelago for the data background is setup to evaluate the proposed method. Domestic/short-sea shipping is also lacking in maritime logistics literature, and this paper attempts to answer the call.

To summarise, the objectives and contributions of this paper are threefold:

1 to introduce the concept of multi-objective optimisation in maritime logistics collaboration, more specifically in joint-routing network design between two liner companies

2 to propose a new method by combining the key concepts and strengths of already established methods but designed for a partial dimension of the problem presented in this paper, and to investigate its properties

3 to show an application example of the proposed method in a domestic shipping of the Indonesian archipelago.

To the best of our knowledge, the ideas behind these objectives have never been reported in any publication. The remainder of this paper is organised as follows: Section 2 reviews the literature related to maritime logistics collaboration, vehicle routing problem (VRP), and multi-objective VRP; Section 3 describes the problem, outlines a brief overview of the supporting methods, and details the proposed methodology; Section 4 discusses the results and findings; and Section 5 concludes the paper and discusses further research possibilities.

\section{Literature review}

Despite the fast growth of containership fleet, research in liner shipping partnership and collaboration is considerably marginal. Panayides and Wiedmer (2011) surveyed 17 academic papers published between 1999 and 2010 in this area and indicated that the majority rests in qualitative ground using methods such as survey, interview, descriptive statistics, or empirical investigation, focusing on wider perspective such as motives for collaboration or strategy development. Quantitative studies, structured with mathematical modelling and analytical investigation on the technical how-to in the execution of the collaboration agenda, are even fewer. Agarwal and Ergun (2010) stated that only a few references on qualitative study on liner shipping alliances are available and a rigorous quantitative study is missing.

From the perspective of the collaborating actors, a number of studies in maritime collaboration are attributed to the partnership of a shipping company and a port terminal rather than between two or more shipping companies. For examples, Boros et al. (2008) optimised the call cycle time of a shipping company to a port; Álvarez-SanJaime et al. (2013) investigated the strategic profitability of a shipping line if it owns a dedicated terminal; and Asgari et al. (2013) compared the competition and cooperation strategies between container hub-ports and shipping companies. Different from the above group, studies concerning company-to-company partnership with sound quantitative analysis include the following. Ding and Liang (2005) used a fuzzy multi-criteria decision making 
approach to setup criteria and model in selecting partners for strategic alliances. Lei et al. (2008) compared three management policies in liner partnerships: the non-collaborative policy, the slot-sharing policy, and the total-sharing (the total collaboration) policy, and concluded that the sharing policies have lots of potential to offer. Yang et al. (2011) investigated the influence of increasing ship size to the stability of alliance by applying the core theory (cooperative game theory) to study the economic performance and stability of liner shipping alliance. Finally, Edisiringhe et al. (2015) studied collaboration between shipping lines through container interchange to deal with container inventory imbalance issue in Sri Lanka.

Routing of fleet is typical research in logistics. The VRP, first introduced by Dantzig and Ramser (1959), is a subset in this field that researchers can turn to for a reference. Eksioglu et al. (2009) reported in their survey that the number of VRP articles between 1985 and 2006 reaches 918. It is not possible to cite the massive literature on VRP; readers can refer to the general reviews by Cordeau et al. (2007) and Eksioglu et al. (2009), or specific reviews by Bräysy et al. (2005) for evolutionary algorithms for VRPTW; Gendreau et al. (2008) for metaheuristics VRP; Josefowiez et al. (2008a, 2008b) for multi-objective VRP; El-Sherbeny (2010) for VRPTW; Archetti and Speranza (2012) for split-deliveries VRP; Vidal et al. (2013) for heuristics for multi-attribute VRP; and Lin et al. (2014) for trends in green VRP.

Given the NP-hardness of VRP, researchers often turn to heuristics or metaheuristics in their approach. The following metaheuristic-based VRP studies are worth mentioning: multiple ant-colony system (MACS) (Gambardella et al., 1999; Silva and Leal, 2011), genetic algorithms (GA) (Prins, 2004, 2009; Ombuki et al., 2006), variable neighbourhood search heuristic (Imran et al., 2009), hybrid metaheuristic combining evolutionary computation and simulated annealing (Baños et al., 2013), and scatter search metaheuristic (Melián-Batista et al., 2014). These papers discuss multiple objectives VRPTW, except Gambardella et al. (1999), Imran et al. (2009), and Prins (2004, 2009). More specifically, Ombuki et al. (2006) and Silva and Leal (2011) formulated total cost/distance and number of vehicles as two objectives to be minimised, whereas Baños et al. (2013) and Melián-Batista et al. (2014) used total cost/distance and workload imbalance as the problem objectives. It should be noted that the last four works assume identical vehicles. For single-objective problems, the GA of Prins (2004) for VRP and Prins (2009) for heterogeneous VRP (HVRP; without considering fixed costs) deserve further spotlight. Prior to the author's works, GAs for VRP had been considered inferior compared to other metaheuristics such as the tabu search (Gendreau et al., 2002). Prins' GA uses tour-splitting procedure, dispersal mechanism, and local search mutation based on memetic algorithms. All these components form the strengths of the GA and are promising to be extended for multi-objective problems.

Shipping companies usually own heterogeneous vessels in terms of speeds and capacities, and fixed cost is an important consideration due to high capital cost of a vessel. For liner shipping with published schedule, time windows are also very critical. To consider these factors altogether (heterogeneity of vessels, time windows, and fixed costs) bring much complexity in the VRP model, which is partly why VRP is rarely applied in maritime logistics and not many VRP studies can be found in the literature for maritime cases. Some research papers in this area are discussed as follows. Sambracos et al. (2004) formulated a VRP and list-based threshold acceptance (LBTA) meta-heuristic in a problem consisting of 13 ports (including a depot port) and 25 sea links. Karlaftis et al. (2009) used a hybridised GA on a hub-and-spoke routing problem for a VRP with 
homogeneous vessels, pickups-deliveries, and time deadlines. Takano and Arai (2009) studied an 18-port hub-and-spoke network problem using GA for heterogeneous vessels. Romero et al. (2013) developed a greedy randomised adaptive search procedure (GRASP) for a ship routing problem added by a knapsack formulation to handle partial deliveries and applied the proposed algorithm in a Chilean sea for a salmon supplier company. Agra et al. (2013) developed a VRPTW model with uncertain travel times for a maritime transportation problem. Lastly, the work of Hsu and Hsieh (2007) also needs to be mentioned in this review. The authors studied routing, ship size, and sailing frequency under hub-and-spoke environment. Although not utilising any VRP model, the authors' multi-objective approach is relevant to the main topic of this paper.

Table 1 Taxonomy of reviewed VRP papers

\begin{tabular}{|c|c|c|c|c|c|}
\hline Author(s) (year) & $\begin{array}{l}\text { Scope of } \\
\text { logistics }\end{array}$ & $\begin{array}{c}\text { Objectiv } \\
e\end{array}$ & $\begin{array}{l}\text { VRP } \\
\text { class }\end{array}$ & $\begin{array}{c}\text { Type of meta- } \\
\text { heuristic }\end{array}$ & $\begin{array}{l}\text { Nature of } \\
\text { vehicles }\end{array}$ \\
\hline $\begin{array}{l}\text { Gambardella et al. } \\
\text { (1999) }\end{array}$ & General & Single & VRPTW & MACS & Identical \\
\hline Prins (2004) & General & Single & VRP & GA & Identical \\
\hline $\begin{array}{l}\text { Sambracos et al. } \\
(2004)\end{array}$ & Maritime & Single & VRP & LBTA & Identical \\
\hline $\begin{array}{l}\text { Ombuki et al. } \\
\text { (2006) }\end{array}$ & General & Multiple & VRPTW & GA & Identical \\
\hline $\begin{array}{l}\text { Hsu and Hsieh } \\
\text { (2007) }\end{array}$ & Maritime & Multiple & - & - & Heterogeneous \\
\hline Imran et al. (2009) & General & Single & HVRP & VNS & Heterogeneous \\
\hline $\begin{array}{l}\text { Karlaftis et al. } \\
(2009)\end{array}$ & Maritime & Single & VRPPD & GA & Identical \\
\hline Prins (2009) & General & Single & HVRP & GA & Heterogeneous \\
\hline $\begin{array}{l}\text { Takano and Arai } \\
(2009)\end{array}$ & Maritime & Single & - & GA & Heterogeneous \\
\hline $\begin{array}{l}\text { Silva and Leal } \\
\text { (2011) }\end{array}$ & General & Multiple & VRPTW & MACS & Identical \\
\hline Agra et al. (2013) & Maritime & Single & VRPTW & - & Heterogeneous \\
\hline $\begin{array}{l}\text { Baños et al. } \\
\text { (2013) }\end{array}$ & General & Multiple & VRPTW & Hybrid & Identical \\
\hline $\begin{array}{l}\text { Romero et al. } \\
\text { (2013) }\end{array}$ & Maritime & Single & VRPTW & GRASP & Heterogeneous \\
\hline $\begin{array}{l}\text { Melián-Batista et } \\
\text { al. (2014) }\end{array}$ & General & Multiple & VRPTW & Scatter search & Identical \\
\hline
\end{tabular}

The metaheuristic VRP studies reviewed in this section are summarised in the taxonomy presented in Table 1. It is clear from Table 1 that a gap is apparent for research in maritime logistics collaboration with multi-objective setting and a metaheuristic approach. Furthermore, a more specific VRP variant that considers distinct attributes of a ship routing problem, i.e., heterogeneous vehicles, time windows, and fixed costs, is also lacking from the literature. This paper aims to develop a methodology for such problems. To adapt the context of VRP in a ship routing problem, few terminologies must be adjusted. The term 'vehicle' will be replaced with 'vessel', 'city' with 'port', and 
'variable cost' with 'bunker cost'. For the purpose of numerical experiments, its application in short-sea shipping (Indonesian archipelago) characterised by such attributes will be demonstrated.

\section{Problem definition}

This section is divided in two sub-sections. The first sub-section describes the problem and its pertinent data, followed by the next sub-section with the formulation of heterogeneous VRP with time windows (HVRPTW).

Table 2 Data of vessels

\begin{tabular}{|c|c|c|c|c|c|c|}
\hline \multicolumn{7}{|c|}{ Carrier $A$} \\
\hline Type & $\begin{array}{l}\text { Capacity } \\
(T E U s)\end{array}$ & $\begin{array}{l}\text { Speed } \\
\text { (knots) }\end{array}$ & $\begin{array}{c}\text { Weekly fixed } \\
\text { cost (USD) }\end{array}$ & $\begin{array}{c}\text { Bunker cost } \\
\text { per nm (USD) }\end{array}$ & $\begin{array}{c}\text { Units } \\
\text { available }\end{array}$ & $\begin{array}{c}\text { Total } \\
\text { capacity }\end{array}$ \\
\hline A1 & $400^{\circ}$ & 13.0 & $81,638.20$ & 3.53 & 1 & 400 \\
\hline $\mathrm{A} 2$ & 500 & 13.5 & $84,756.00$ & 4.02 & 2 & 1,000 \\
\hline A3 & 650 & 16.5 & $89,432.70$ & 7.54 & 2 & 1,300 \\
\hline A4 & 850 & 14.0 & $95,668.30$ & 4.77 & 1 & 850 \\
\hline Total & & & & & 6 & 3,550 \\
\hline \multicolumn{7}{|c|}{ Carrier B } \\
\hline Type & $\begin{array}{c}\text { Capacity } \\
\text { (TEUs) }\end{array}$ & $\begin{array}{l}\text { Speed } \\
\text { (knots) }\end{array}$ & $\begin{array}{l}\text { Weekly fixed } \\
\text { cost (USD) }\end{array}$ & $\begin{array}{c}\text { Bunker cost } \\
\text { per nm (USD) }\end{array}$ & $\begin{array}{c}\text { Units } \\
\text { available }\end{array}$ & $\begin{array}{c}\text { Total } \\
\text { capacity }\end{array}$ \\
\hline B1 & 450 & 13.5 & $83,197.10$ & 3.98 & 1 & 450 \\
\hline B2 & 700 & 16.5 & $90,991.60$ & 7.61 & 1 & 700 \\
\hline B3 & 850 & 17.5 & $95,668.30$ & 9.32 & 1 & 850 \\
\hline Total & & & & & 3 & 2,000 \\
\hline
\end{tabular}

\subsection{Problem description}

Two domestic liner shipping companies operate from the same depot and serve several ports/cities in the Indonesian archipelago. Both companies (carriers) plan to collaborate by joining their service routes via capacity sharing to increase the utilisation of their vessels. Capacity sharing means Carrier A will allocate a portion of its capacity to be used by Carrier B going to a number of ports-of-call, such that Carrier B does not have to use its own vessels going to the same destination (except if the demand is high and cannot be served by one vessel), and vice versa. The problem on hand is how to design the new joint routing network resulting from the collaboration, optimising two objectives; namely, total costs and fairness in cost-sharing distribution. The first objective is straightforward and typical in optimisation programming. This objective is preferred over profit maximisation since all demands are assumed to be satisfied, thus the same amount of profit will be generated. The second objective is part of the novelty of this paper, and its formulation is motivated by the collaboration background in the problem. The idea is, while costs are minimised, the distribution of total cost should be in a fair proportion that is acceptable by the collaborating parties. 
The carriers are of different sizes: Carrier A is larger than Carrier B in terms of fleet size and port demands. Carrier A owns six vessels and Carrier B has three vessels, all in the category of feeder vessels with capacities in the range of 400 to 850 TEUs (20-foot equivalent units) and speeds in 13-17.5 knots. The costs of vessels are extrapolated from those of larger ships in Stopford (2009), without inflation adjustment. Two cost components include weekly fixed/overhead costs and variable costs measured as bunker cost per nautical mile at a certain speed. Data of vessels are listed in Table 2. Note that the fixed costs are relatively high and therefore they cannot be ignored as in the case with most VRP studies.

Data of ports-of-call are listed in Table 3 and the geographical spread of the cities is shown in Figure 1. Port demands are estimated from OECD (2012) where domestic throughputs of containers are reported. The figures are converted to weekly demands and $2.5 \%$ is assumed for the demand of Carrier A and $1.25 \%$ for Carrier B. Demand of Jakarta is very large and cannot be served by any of the vessel in the combined fleet, thus for simplicity it is evenly split and half of it is assigned to a dummy city at the same coordinate, making a total of 13 ports-of-call excluding the depot Surabaya. Service times are incurred in ports by a constant of eight hours plus a fixed 40-container-per-hour unloading times, except for the depot where only eight hours of service time are assumed. Finally, time windows are formulated as due dates of the ports-of-call. Only upper time windows that represent due dates are formulated and none of these due dates exceeds seven days, hence corresponds to a weekly liner service which is equivalent to the period of demands.

Figure 1 Map of Indonesia with cities being studied (see online version for colours)

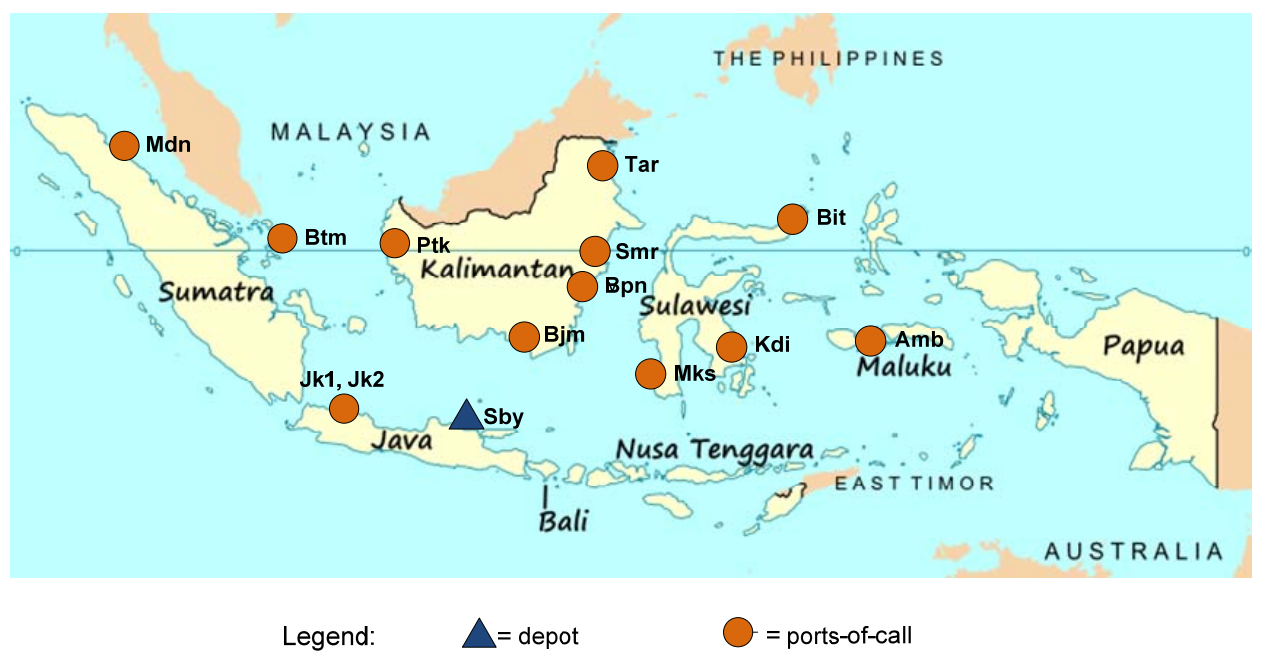

Distances between ports are measured using distancecalculator.globefeed.com. These are Euclidean distances and therefore need to be adjusted to reflect sea distance instead of land distance, e.g., between Ptk and Smr/Bpn. Adjustment factors are within the range of $103 \%-180 \%$ and triangular relationships are maintained in all distances. Data of distances are detailed in the following URL: http://ti.ubaya.ac.id/index.php/component/ content/article/24-dosen/177-wibisono-jittamai-2015.html. 
Table 3 Data of ports

\begin{tabular}{|c|c|c|c|c|c|c|c|c|c|}
\hline \multirow[b]{2}{*}{ No. } & \multirow[b]{2}{*}{ City } & \multirow[b]{2}{*}{ Abbrev. } & \multirow{2}{*}{$\begin{array}{c}\text { Due } \\
\text { date } \\
\text { (hours) }\end{array}$} & \multicolumn{2}{|c|}{ Carrier A } & \multicolumn{2}{|c|}{ Carrier B } & \multicolumn{2}{|c|}{ Total } \\
\hline & & & & $\begin{array}{c}\text { Demand } \\
\text { (TEUs) }\end{array}$ & $\begin{array}{c}\text { Port } \\
\text { time } \\
\text { (hours) }\end{array}$ & $\begin{array}{c}\text { Demand } \\
\left(T E U_{S}\right)\end{array}$ & $\begin{array}{c}\text { Port } \\
\text { time } \\
\text { (hours) }\end{array}$ & $\begin{array}{c}\text { Demand } \\
\text { (TEUs) }\end{array}$ & $\begin{array}{l}\text { Port } \\
\text { time } \\
\text { (hours) }\end{array}$ \\
\hline 1 & Samarinda & $\mathrm{Smr}$ & 66 & 46 & 9.15 & 23 & 8.58 & 69 & 9.73 \\
\hline 2 & Balikpapan & Bpn & 66 & 17 & 8.43 & 8 & 8.20 & 25 & 8.63 \\
\hline 3 & Banjarmasin & Bjm & 54 & 57 & 9.43 & 28 & 8.70 & 85 & 10.13 \\
\hline 4 & Kendari & Kdi & 90 & 7 & 8.18 & 0 & 0 & 7 & 8.18 \\
\hline 5 & Makassar & Mks & 66 & 119 & 10.98 & 60 & 9.50 & 179 & 12.48 \\
\hline 6 & Ambon & $A m b$ & 108 & 7 & 8.18 & 0 & 0 & 7 & 8.18 \\
\hline 7 & Tarakan & Tar & 108 & 8 & 8.20 & 0 & 0 & 8 & 8.20 \\
\hline 8 & Bitung & Bit & 126 & 30 & 8.75 & 15 & 8.38 & 45 & 9.13 \\
\hline 9 & Medan & Mdn & 126 & 134 & 11.35 & 0 & 0 & 134 & 11.35 \\
\hline 10 & Pontianak & Ptk & 90 & 48 & 9.20 & 0 & 0 & 48 & 9.20 \\
\hline 11 & Jakarta1 & $\mathrm{Jk} 1$ & 78 & 400 & 18.00 & 200 & 18.00 & 600 & 23.00 \\
\hline 12 & Jakarta2 & $\mathrm{Jk} 2$ & 78 & 400 & 13.00 & 200 & 13.00 & 600 & 23.00 \\
\hline 13 & Batam & Btm & 102 & 13 & 8.33 & 0 & 0 & 13 & 8.33 \\
\hline Total & & & 1,286 & & 534 & & & & \\
\hline
\end{tabular}

\subsection{Heterogeneous VRP with time windows (HVRPTW)}

A VRP is commonly represented as a complete undirected graph $\mathcal{G}=(\mathcal{N}, \mathcal{A})$ with a node set $\mathcal{N}=(0,1, \ldots, N)$ and an arc set $\mathcal{A}$. Node 0 is the depot and the remaining nodes $\mathcal{C} \in \mathcal{N} \backslash\{0\}$ represent the customers, each of which has a non-negative demand. A non-negative travel cost $c_{i, j}$ is associated with each $\operatorname{arc}(i, j) \in \mathcal{A}$ and corresponds to the cost incurred for traversing the arc. The problem is called a symmetric VRP if $c_{i, j}=c_{j, i}$ for all arcs in $\mathcal{A}$. A VRP problem statement is to determine a set of vehicle trips that optimise certain objective(s), such that:

1 each vehicle starts from and returns to the depot

2 each customer is visited exactly only once

3 total demand in each trip does not exceed the vehicle capacity.

In a VRPTW, customer $i$ has to be visited within a certain time frame $\left[e_{i}, l_{i}\right]$ where $e_{i}$ is the earliest time and $l_{i}>0$ is the latest time of a visit. A single-sided time window $e i=0$ and $l_{i}>0$ is equivalent to imposing a due-date to the service. In liner shipping where schedule is a key attribute, arrival times at the ports-of-call are important part of the service for the customers. Define set $\mathcal{V}$ as the set of vessels indexed by $v$, each vessel has capacity $C^{v}$, fixed cost $f^{v}$, and variable cost $c_{i, j}^{v}$ The demands to be satisfied in $\mathcal{C}$ are represented by $D_{i}$. Before presenting the formulation, the following sets and parameters need to be defined. 
$\mathcal{C}$ set of carriers, indexed by $a$

$\mathcal{V}$ set of vessels of carrier $a$, indexed by $v$

$\mathcal{A} \quad$ set of $\operatorname{arcs}(i, j)$ denoting a flow from port $i$ to port $j$

$\mathcal{N}$ set of all ports $\mathcal{N}=\{0,1 \ldots, N\} ;\{0\}$ is the depot

$\mathcal{P}$ set of customers, or $\mathcal{N} \backslash\{0\}$

$f^{a, v} \quad$ weekly fixed cost of vessel $v$ of carrier $a$

$c_{i, j}^{a, v}$ travel cost of vessel $v$ of carrier $a$ if it goes from port $i$ to port $j$

$t_{i, j}^{a, v} \quad$ travel time of vessel $v$ of carrier $a$ if it goes from port $i$ to port $j$

$C^{a, v}$ capacity of vessel $v$ of carrier $a$

$D i \quad$ total demand of all carriers at port $a$

$T_{i} \quad$ due date of ship arrival time at port $i$

$p_{i} \quad$ service time at port $i$

$M \quad$ a large constant

$x_{i, j}^{a, v}$ binary variables for vessel $v$ of carrier $a$ in $\operatorname{arc}(i, j) ; x_{i, v}^{a, v}=1$ if the vessel traverses $\operatorname{arc}(i, j)$ and equals 0 otherwise

$s_{i}^{a, v}$ time window for vessel $v$ of carrier $a$ at port $i$.

The multiple carriers HVRPTW can be formulated as follows:

$$
\text { Minimise } \sum_{a \in \mathcal{C}} \sum_{v \in \mathcal{V}}\left(\sum_{j \in \mathcal{A}} f^{a, v} \cdot x_{0, j}^{a, v}+\sum_{i, j \in \mathcal{A}} x_{i, j}^{a, v} \cdot c_{i, j}^{a, v}\right)
$$

Subject to:

$$
\begin{aligned}
& \sum_{a \in \mathcal{C}} \sum_{v \in \mathcal{V}_{a}} \sum_{i, j \in \mathcal{A}} x_{i, j}^{a, v} \cdot c^{a, v} \geq D_{i} \quad \forall i \in \mathcal{P} \\
& \sum_{i \in \mathcal{P}} D_{i} \sum_{j \in \mathcal{N}} x_{i, j}^{a, v} \leq C^{a, v} \quad \forall a \in \mathcal{C} ; v \in \mathcal{V}_{a} \\
& \sum_{i \in \mathcal{N}} x_{i, k}^{a, v}-\sum_{j \in \mathcal{N}} x_{k, j}^{a, v}=0 \quad \forall k \in \mathcal{P} ; a \in \mathcal{C} ; v \in \mathcal{V} \\
& x_{0, j}^{a, v}=0 \quad \forall i \in \mathcal{N} ; a \in \mathcal{C} ; v \in \mathcal{V}_{a} \\
& s_{i}^{a, v} \leq T_{i} \quad \forall i \in \mathcal{P} ; a \in \mathcal{C} ; v \in \mathcal{V}_{a} \\
& s_{i}^{a, v}+t_{i, j}^{a, v}+p_{i}-M\left(1-x_{i, j}^{a, v}\right) \leq s_{j}^{a, v} \quad \forall i \in \mathcal{N} ; j \in \mathcal{P} ; a \in \mathcal{C} ; v \in \mathcal{V}_{a} \\
& s_{i}^{a, v}+t_{i, j}^{a, v}+p_{i}-M\left(1-x_{i, j}^{a, v}\right) \leq s_{j}^{a, v} \quad \forall i \in \mathcal{N} ; j \in \mathcal{P} ; a \in \mathcal{C} ; v \in \mathcal{V}_{a}
\end{aligned}
$$




$$
\begin{aligned}
& x_{i, j}^{a, v} \in\{0,1\} \quad \forall i, j \in \mathcal{A} ; a \in \mathcal{C} ; v \in \mathcal{V}_{a} \\
& s_{0}^{a, v}=0 \quad \forall a \in \mathcal{C} ; v \in \mathcal{V}_{a} \\
& s_{i}^{a, v} \geq 0 \quad \forall i \in \mathcal{N} ; a \in \mathcal{C} ; v \in \mathcal{V}_{a}
\end{aligned}
$$

The objective function (1) minimises total cost that is composed of the fixed cost if a vessel is used, and the variable cost derived from the travel cost. Constraints (2) and (3) warrant demand fulfilment in each port without violating capacity of the vessel used. Constraints (4) balance the incoming and outgoing trips in each port. The next two sets of constraints regulate the trips by preventing looping in the same node in (5) and assigning not more than one tour to one vessel in (6).

Time windows are formulated by introducing variables $s_{i}^{a, v}$ that represent the time vessel $v$ of carrier $a$ starts to service customer $i$. Constraints (7) are the upper-bound of $s_{i}^{a, v}$ and constraints (8) indicate that a vessel cannot arrive at port $j$ before $s_{i}^{a, v}+$ travel time from port $i$ to port $j+$ service time at port $i$. If arc $(i, j)$ is not traversed by vessel $v$ of carrier $a\left(x_{i, j}^{a, v}=0\right)$, the constraints become redundant due to $M$. Sub-tour breaking constraints are not required as their function is replaced by constraints (7) and (8). The rest of the equations describe the nature of decision variables. Variables $x_{i, j}^{a, v}$ are binary integer and $s_{i}^{a, v}$ are continuous, thus the model is a mixed integer programming.

\section{Methodology}

In this section, the first sub-section presents overview of the basic methods that form the foundation of the proposed method. The proposed method will be outlined afterwards.

\subsection{Overview of the basic methods}

In addition to the linear programming formulation, this paper proposes a new method inspired by two different methods, each of which is oriented towards a different background of the problem. First, NSGA-II (elitist non-dominated sorting genetic algorithm) from Deb et al. (2000) will be used to tackle the multi-objective part. Second, aggressive but effective GA for VRP/HVRP from Prins $(2004,2009)$ will be responsible for the routing part. The strengths of these two methods are combined and used to build a method to find the Pareto optimal set of the particular problem discussed in this paper. The method can therefore be considered as a hybrid multi-objective metaheuristic.

\subsubsection{Elitist non-dominated sorting genetic algorithm (NSGA-II)}

One approach in multi-objective optimisation (MOO) is finding a set of non-dominated solutions, also called the Pareto set. Non-dominated set is defined as follows. Suppose we have two objective functions $f_{1}$ and $f_{2}$, both are to be minimised, and $f_{1}^{1}$ and $f_{2}^{1}$ are the solutions of decision vector $x^{1}$ for $f_{1}$ and $f_{2}$, respectively, and $f_{1}^{2}$ and $f_{2}^{2}$ are the solutions of decision vector $x^{2}$ for $f_{1}$ and $f_{2}$, respectively. It is said that $x^{1}$ 
dominates $x^{2}$ if at least one component of $f^{1}$ is smaller than the corresponding component of $f^{2}$ and none is greater. If, for example, $f_{1}^{1}$ is smaller than $f_{1}^{2}$ but $f_{2}^{1}$ is greater than $f_{2}^{2}$, or on the contrary, $f_{1}^{1}$ is greater than $f_{1}^{2}$ but $f_{2}^{1}$ is smaller than $f_{2}^{2}$, no solution dominates the other and these are referred as the Pareto or non-dominated set of optimal solutions (Zitzler et al., 2003). Another approach in MOO is by assigning a weight vector to the objective functions, thereby allowing aggregation of the objectives into a single function and transforming the problem to a single-objective optimisation. However, in reality, quantifying such precise weights is all but a simple task even for experienced users in the field. The Pareto approach is free from such problem and it returns several alternative solutions to the decision makers who can exercise other higher-level considerations that probably have not been embedded in the model. This approach is more practical especially when decision makers are indecisive of the weights or when a trade-off relation of objective functions is not a priori known.

Figure 3 Example of order crossover operator

\begin{tabular}{|c|c|c|c|c|c|c|c|c|}
\hline & & & & $i=4$ & & $j=6$ & & \\
\hline & & & & $\downarrow$ & & $\downarrow$ & & \\
\hline P1: & 4 & 8 & 7 & 3 & 6 & 5 & 2 & 10 \\
\hline P2: & 3 & 5 & 4 & 2 & 7 & 9 & 10 & 8 \\
\hline $\mathrm{C} 1:$ & 2 & 7 & 9 & 3 & 6 & 5 & 10 & 8 \\
\hline $\mathrm{C} 2:$ & 3 & 6 & 5 & 2 & 7 & 9 & 4 & 10 \\
\hline
\end{tabular}

NSGA-II is an MOO technique based on evolutionary search algorithm proposed by Deb et al. (2000) as a refinement from the earlier version of the algorithm called NSGA from Srinivas and Deb (1994). A significant difference between the two methods is that NSGA-II uses an elite-preserving mechanism to prevent good solutions from being discarded by the genetic operators during iterations. After an initial parent population is generated, crossovers are performed to produce child population. Both populations are then combined and a number of best solutions, dictated by population size, from the combined population are carried out to the subsequent iterations. NSGA-II classifies population members based on ranks and distance measures which set the criteria to determine best solutions. The procedure is called crowding distance selection, and its intuitive explanation can be described by referring to Figure 3. In this Figure, the shaded area is the feasible region in the solution space of two objective functions $f_{1}$ and $f_{2}$, and the true Pareto front for a min-min problem (minimisation of both objective functions) is indicated by the bold curve line $A-B$. From any point of solution in the feasible region, the search in NSGA-II progresses towards the Pareto front $A-B$. The algorithm sorts the solutions based on non-domination principles and assigns a rank to each non-dominated front. In Figure 3, in addition to $A-B$, two Pareto fronts are depicted, i.e., lines $a-e$ and 13. The line $a$-e has a higher rank than line 1-3 because it is closer to the true Pareto front $A-B$, so with population size of five, solutions $a, b, c, d$ and $e$ will pass to the next stage and become the new parent population whereas solutions 1,2 and 3 will be eliminated.

If the population size is less than five, the solutions a-e compete and this is where the distance measures have their role. In addition to progressing as close as possible (and as fast as possible) to the true Pareto front, another concern in any MOO technique is the 
spread of the found Pareto members. The wider is the spread, the higher is the quality of solutions. As seen in Figure 3, solutions $a$ and $e$ that lie in the edges of the highest-rank Pareto front are given highest distance measure to guarantee them of being selected to the next iteration. Solutions in the 'inner' part of that front $(b, c, d)$ are given distance measures based on how crowded their locations are relative to the adjacent solutions. Using this principle, following solutions $a$ and $e$, the descending order of the remaining solutions in that front is $d, c$ and $b$. Therefore, if only four solutions are to be taken to the next round, solutions $1,2,3$ and $b$ will be left out.

\subsubsection{Prins'genetic algorithm}

Prins (2004) developed a simple yet effective GA for the basic VRP and extended his work for HVRP (Prins, 2009). The strengths of the GAs come from the formulation of tour-splitting procedure called Split, dispersal mechanisms to prevent identical solutions (clones) in the population, and mutation operator using local search. The first component helps partition the chromosomes into feasible trips while the latter two components are the key for faster convergence of the GAs to the best solution.

Split transforms the original distance matrix of cities to an acyclic auxiliary graph $\mathcal{H}=(\mathcal{N}, \mathcal{A})$, then works on this graph as a minimum-cost path problem. The purpose of the procedure is to partition a chromosome of permutation of ports (without trip delimiters) to a set of feasible trips. Feasibility of the trips can be tested against constraints such as vessel capacities, time windows, etc. For HVRP cases, complexity of the problem increases and necessitates a dynamic programming approach. The increasing complexity also leads to possibility for infeasible splitting.

The population is managed using some kind of memetic algorithm with two integral components: dispersal mechanisms and local search mutation. In Prins (2009), two types of dispersal mechanism are tested. The first mechanism measures the distance $d(A, B)$ as the number of pairs of adjacent cities in chromosome $A$ that are no longer adjacent in chromosome $B$. Suppose $A=(1,2,3,4,5)$ and $B=(3,1,4,5,2)$, then $(1,2),(2,3)$ and $(3,4)$ are no longer adjacent in $B$, thus $d(A, B)=3$. Given $D(P, C)$ as the minimum distance of a new chromosome $C$ to population $P$ and a non-negative threshold distance limit $(D L), C$ is accepted as a population member if and only if (12) holds, where $n=$ number of cities. The value of DL changes throughout GA generations, either increasingly or decreasingly, proportionate to the number of iterations. For example, with $n=13,50$ generations, and increasing DL, $D L=1$ would be assigned for generations 1 to $16, D L=2$ for generations 17 to 32 , and $D L=3$ for the rest.

$$
D(P, C)>D L \quad D L \in\{1 . .0 .25 \times(n-1)\}
$$

The second mechanism is controlled by a parameter called the dispersal value (DV) that also serves as a threshold for accepting new population members. The gap of fitness value between the new chromosome $C$ and all other chromosomes in population $P$ is measured and $C$ is accepted if and only if (13) holds, or in other words if the fitness-value gap of the new chromosome $C$ and each of the other chromosomes in $P$ is larger than the $D V(p t=$ chromosome number $\mathrm{t}$ in the population; $S=$ population size $)$.

$$
\left|F(C)-F\left(p_{t}\right)\right|>D V \quad \forall t=1 . . S
$$


The dispersal mechanisms as explained above maintain the population on being spaced, which is an important factor for faster convergence of the search process. Another trick in the population management of Prins' GA is the inclusion of several good chromosomes at the start of iterations so the search has a good several starting points. This is achieved by employing some heuristics in GA for VRP (Prins, 2004) and random generation of chromosomes followed by Split in GA for HVRP (Prins, 2009).

In the main iterations, binary tournament is performed to select two parent members. These parents then 'mate' using order crossover (OX) operator (see an example in Figure 3 with crossover points at the $4^{\text {th }}$ and $6^{\text {th }}$ nodes) to produce two children, but only one will be selected and join the population if it satisfies the spaced criteria as regulated by the dispersal mechanism. A mutation process is triggered with probability pm and it alters the chromosome structure of the new child. The mutation operator uses a local search that works by scanning the $O\left(n^{2}\right)$ neighbourhoods of $n$ (cities) via a sequence of moves as shown in Figure 4. Each time an improvement is made by any move, the process restarts from move one and it goes on until no improvement can be made by the last move. This version of local search is called $L S_{1}$ and works well on HVRP cases where all vehicles are used. Further local search is possible by considering changes of the trips' vehicles. This is called $L S_{2}$ and it works by scanning both the $O\left(n_{2}\right)$ neighbourhoods of $n$ (cities) and $O\left(k^{2}\right)$ neighbourhoods of $k$ (vehicles). The complexity of $L S_{1}$ is $O\left(n^{2}\right)$ but that of $L S_{2}$ is $O\left(n^{2} k^{2}\right)$ since the latter scan takes place inside the former. In other words, $L S_{2}$ is more powerful than $L S_{1}$ but much slower.

Figure 4 Local search mutation operator

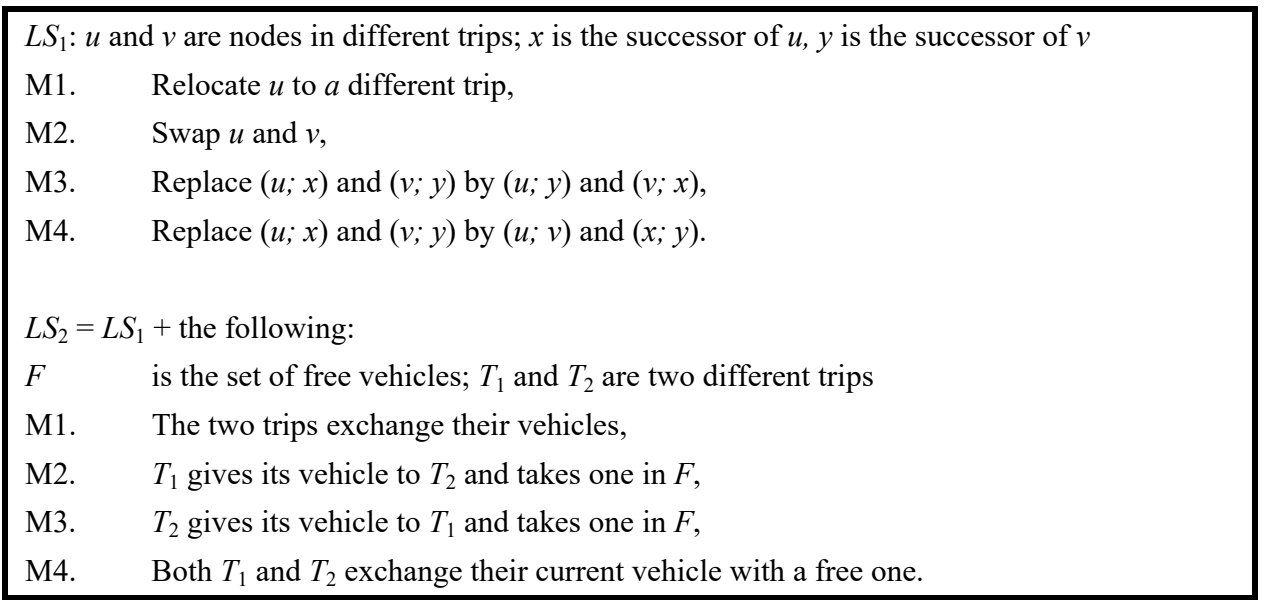

\subsection{Model development}

One of the objectives of this paper is to introduce the concept of multi-objective optimisation in maritime logistics collaboration, more specifically in the scope of joint-routing network design. There have been a number of studies on multi-objective VRPTW as discussed in Section 2, but none considers the use of heterogeneous vehicles that also considers fixed costs because they are not oriented toward the applications in maritime logistics. Furthermore, in some of the studies, in addition to the natural total cost/time/distance minimisation as the first objective, the second objective is formulated 
as minimisation of the number of vehicles. If the fixed cost of vehicles is very significant as in the case in shipping, these two objectives will be very likely correlated and the problem can be treated as a single-objective problem.

In this paper, we propose a second objective that reflects a fair distribution of the total cost. Such a distribution is considered fair if its proportion is in line with the proportion of the capital contributed to the joint operations. The deviation between the targeted and actual total costs of each carrier is calculated, summed for all carriers, and subject to minimisation. Wibisono and Jittamai (2015) proposed the idea of this sharing policy and named it proportionate-sharing policy. The authors also showed that the policy leads to a smaller variance compared to the other sharing policies, thus is more reliable for planning. Before moving forward with formulation of the objectives, we need to introduce the parameters $q_{A}$ as the cost proportion of Carrier $A$ and $q_{B}=1-q_{A}$ as the cost proportion of Carrier $B$. Recall in our data in sub-section 3.1 that Carrier $A$ contributes six vessels and Carrier $B$ contributes three vessels to the joint fleet, thus $q_{A}=\frac{2}{3}$ and $q_{B}=\frac{1}{3}$.

The total cost in equation (1) needs to be broken down for each carrier to ease readability and we have (14) for the total cost of Carrier A and (15) for the total cost of Carrier $B$.

$$
\begin{aligned}
& \sum_{v \in \mathcal{V}_{A}}\left(\sum_{j \in \mathcal{A}} f^{a, v} \cdot x_{0, j}^{a, v}+\sum_{i, j \in \mathcal{A}} x_{i, j}^{a, v} \cdot c_{i, j}^{a, v}\right)=T C_{A} \\
& \sum_{v \in \mathcal{V}_{B}}\left(\sum_{j \in \mathcal{A}} f^{a, v} \cdot x_{0, j}^{a, v}+\sum_{i, j \in \mathcal{A}} x_{i, j}^{a, v} \cdot c_{i, j}^{a, v}\right)=T C_{B} \\
& T C_{A}-q_{A}\left(T C_{A}+T C_{B}\right)=\delta_{A} \\
& T C_{B}-q_{B}\left(T C_{A}+T C_{B}\right)=\delta_{B}
\end{aligned}
$$

Define $\delta_{A}$ as the total cost of Carrier A minus its targeted proportionate cost (16), and, likewise, $\delta_{B}$ for the total cost minus the targeted proportionate cost of Carrier B (17). Now, we are ready to formulate the dual objectives of the problem as follows, subject to the same set of constraints (2) to (12):

$$
\begin{aligned}
& \text { Minimise } T C_{A}+T C_{B} \\
& \text { Minimise }\left|\delta_{A}\right|+\left|\delta_{B}\right|
\end{aligned}
$$

The second objective function (19) minimises total absolute deviation of discrepancies between carrier's fair cost proportion and carrier's total cost. This equation is nonlinear but can be transformed to a linear form using (20)-(22).

$$
\begin{aligned}
& \text { Minimise }|a-b|=\text { Minimise max. }\{a-b, b-a\}=\text { Minimise } y \\
& y \geq a-b \\
& y \geq b-a
\end{aligned}
$$

The single-objective HVRPTW in 3.2 is run to find the optimal route of each carrier separately using each carrier's data of vessels and demands. The resulting total costs of all carriers are summed and compared to the joint-routing total cost to validate the 
financial impact of collaboration. Next, the dual-objective HVRPTW is minimised and maximised on each objective. The obtained minimum values on each objective are none other than points $A$ and $B$ in Figure 2, i.e., the extreme points in the true Pareto front. These two solutions alone may not suffice as decision alternatives given their extreme nature where one best solution is achieved at the expense of the other. However, these are nonetheless true Pareto points, therefore cannot be ignored. As part of the elitism principle of NSGA-II, these solutions will be included and always kept as population members. As to the maximum values, these are needed as required parameters in the crowding distance procedure of the algorithm. Lingo 11.0 on an Intel i5-2430M processor running at $2.4 \mathrm{GHz}$ and $4 \mathrm{MB}$ of RAM on Windows 7 Ultimate is used for the above optimisation.

Figure 2 NSGA-II ranking principles (see online version for colours)

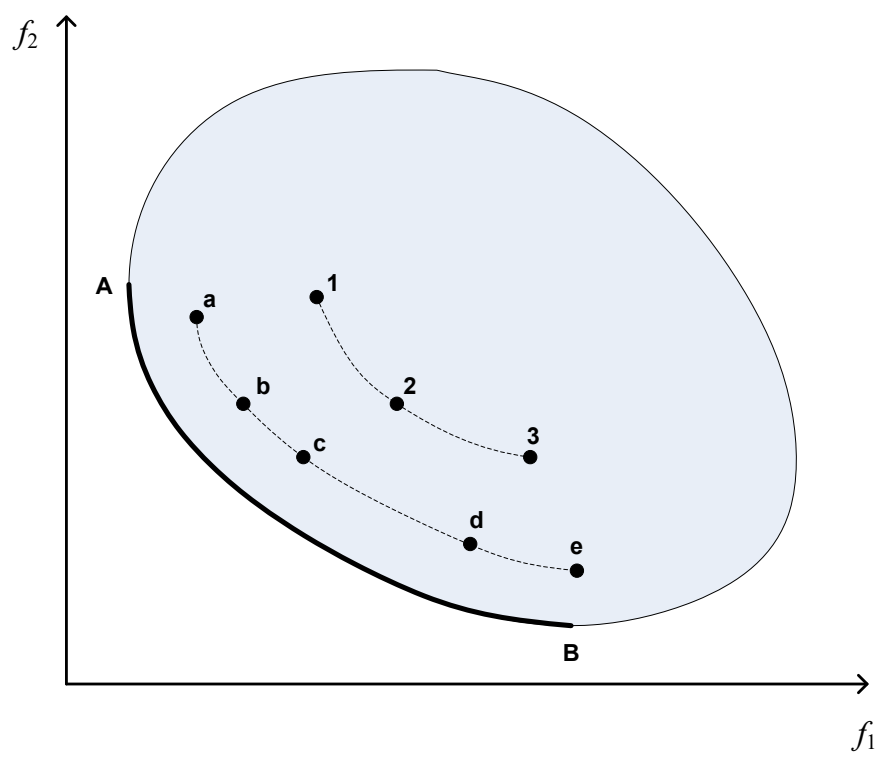

After the key parameters are found by means of optimisation, the search algorithm is performed using Matlab R2100b on the same computer. The algorithm is developed by combining the principles of NSGA-II for the multi-objective part and Prins' GA for the evolutionary search process. The main algorithm is detailed in Figure 5. After input data and parameters are read, the parent population is initialised. The population is halved and each group weighs on each objective. This approach is necessary because on every solution (chromosome) that is generated by random permutation, Split is called to form the trip partition and the procedure needs to know on what ground a good partition should be constructed. Population number one uses the minimum-cost solution already found by the linear programming optimisation. Population number two is built with the ray heuristic that works by forming a rotating ray centred at the depot with the zero degree starts at West. This heuristic is very suited to the problem given the relative position of the depot to the other ports where the depot is centrally located. A cost-based Split (splitcost) is then performed on this second chromosome. The inclusion of good solutions in the initial population can help jump-start the search exploration. Population number 
three up to half of the population size are generated randomly, each is evaluated by Split and spaced criteria according to the dispersal mechanism being used. The other half of parent population are generated in a similar fashion: population number $($ halfpop +1$)$ uses the minimum-deviation solution; population number $($ halfpop +2$)$ uses ray heuristic evaluated by deviation-based Split (splitdevn); and the rest of the population use random generation, evaluated by splitdevn and spaced criteria.

Figure 5 MOEA-HVRPTW main algorithm

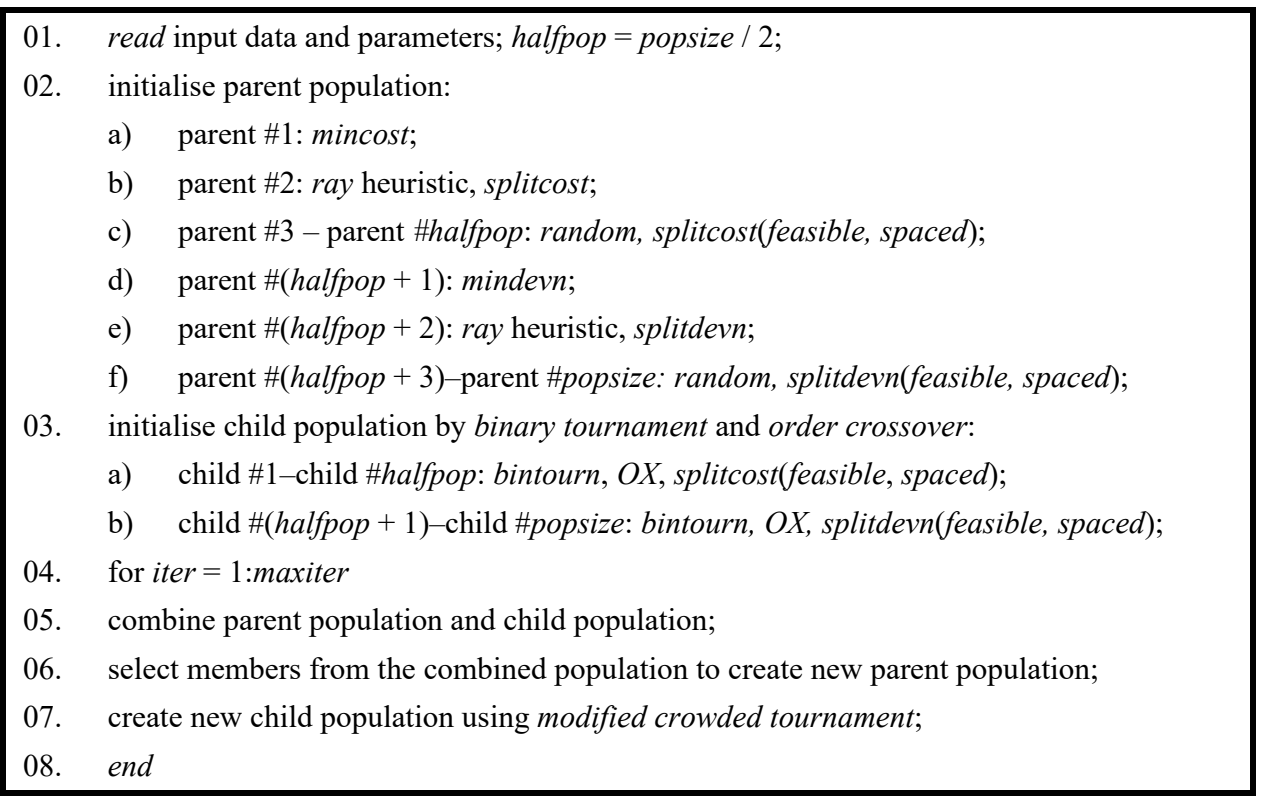

Afterward, a population of child is initialised. The regular binary tournament is applied to select two parents to produce offspring using order crossover operator. As in the parent initialisation, splitcost, splitdevn and spaced criteria are the backbone of the process. With one parent population and one child population, the iterations can start. These are executed through lines $04-08$, which are standard NSGA-II iterations except for line 07 where some principles of Prins' GA are inserted in the algorithm to form the modified crowded tournament. The pseudo-code of this procedure is listed in Figure 6.

The pseudo-code in Figure 6 is more detailed than that of the main algorithm in Figure 5 for better clarification of this important procedure. The code is listed for the creation of only half of the targeted new child population. The creation of the other half is a replication and the only change needed is to replace splitcost with splitdevn so each half of the new child favours each of the two objectives.

The parent population becomes an input to this procedure. Two parents are selected randomly, then compete via the crowded tournament. The working principle of crowded tournament is basically as explained on Figure 2: two chromosomes are compared based on their ranks; if the ranks are equal, then their distance measures become the deciding criteria. Two random parents again compete and the two winners perform crossover to produce child chromosome $C$ (lines 5-6). Splitcost then detects whether $C$ can be feasibly partitioned into trips (lines 7-10) and if successful, the rest of the lines are executed. If mutation is triggered, $C$ is improved by a local search on trip and vessel exchanges, and 
temporarily copied to $M$ (lines 11-12). Next, $M$ is compared to all members of the first-rank Pareto set on its non-domination status. If $M$ is not dominated by all first-rank Pareto members, then it is marked for acceptance (lines 13-15). This test is called overriding rule since if it is passed, spaced requirement is no longer checked.

Figure 6 Modified Crowded tournament procedure (for half population)

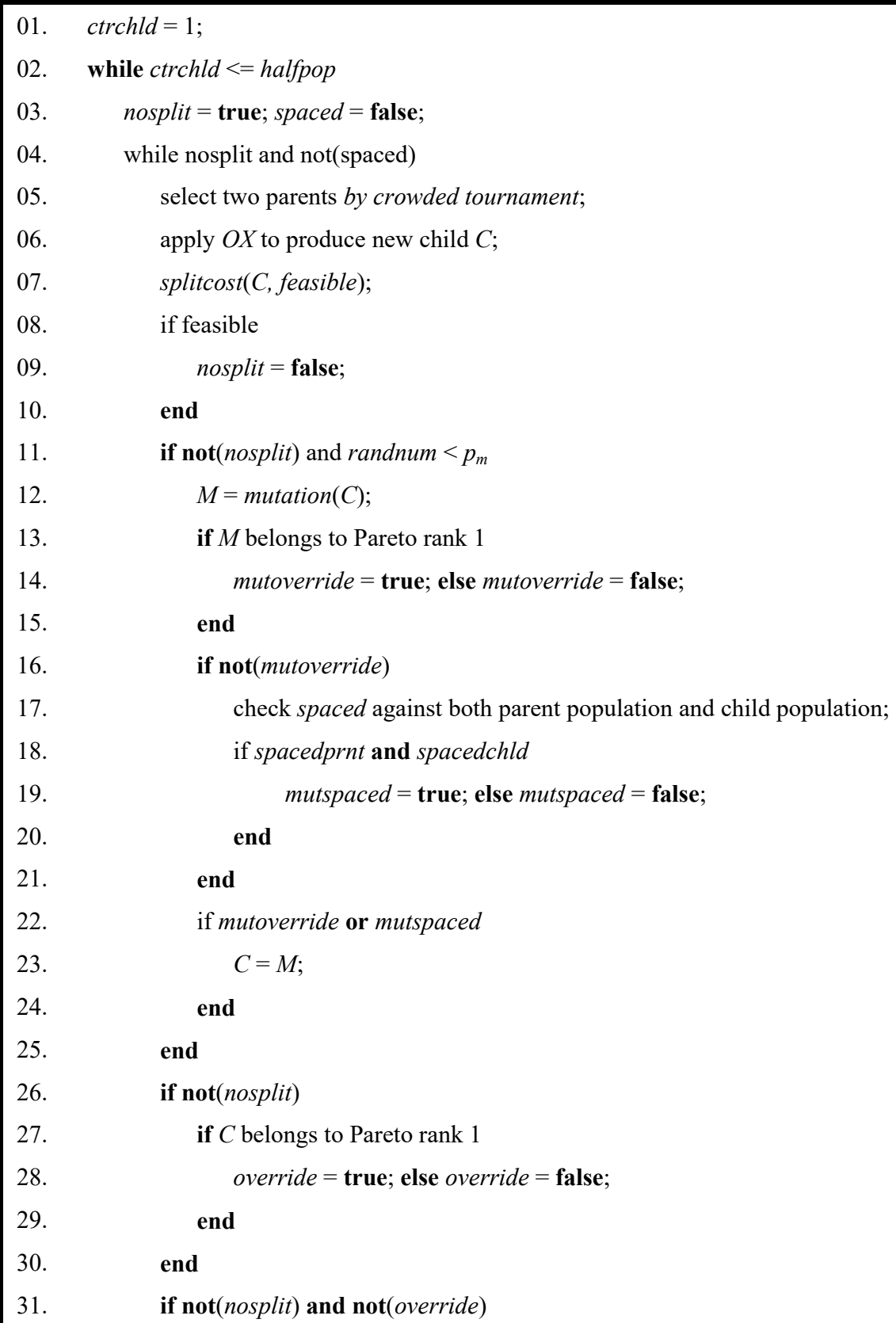


Figure 6 Modified Crowded tournament procedure (for half population) (continued)

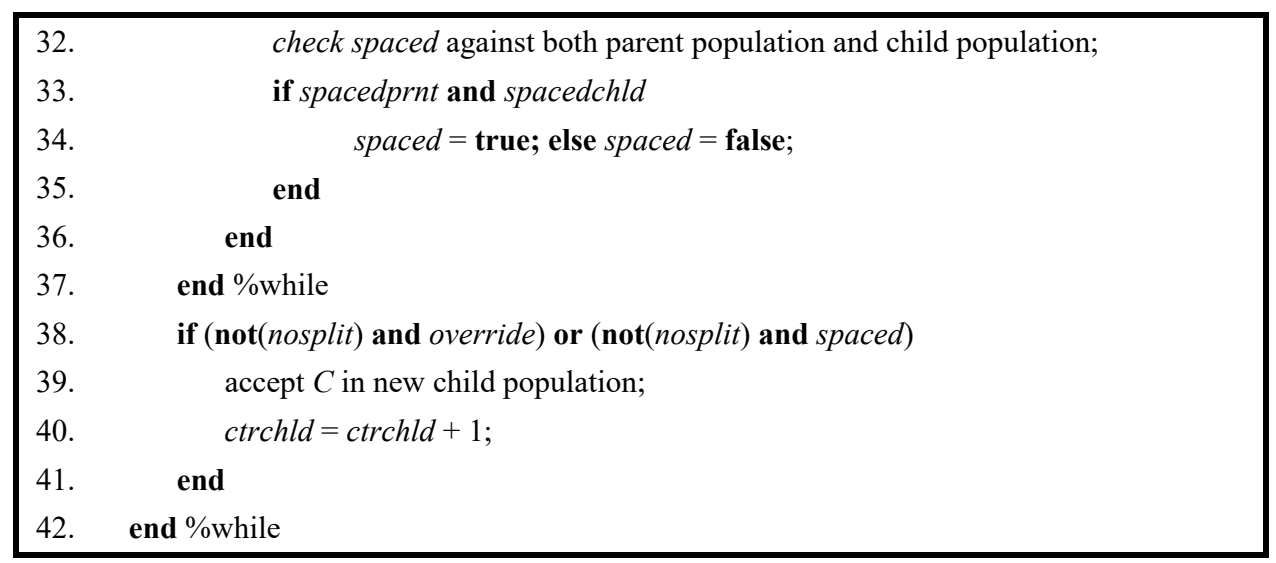

If the new mutated chromosome $\mathrm{M}$ does not belong to the first-rank Pareto, it is tested for spaced criteria against both parent and child populations (lines 16-21). If either of the overriding or spaced tests passes, $\mathrm{M}$ is copied back to $\mathrm{C}$ (lines 22-24). The temporary copy of $\mathrm{C}$ to $\mathrm{M}$ is necessary since if mutation is not triggered, $\mathrm{C}$ is subject to the same tests for overriding rule (lines 26-30) and spaced criteria (lines 31-36). Finally, if either of the tests on $\mathrm{C}$ passes (and Split is feasible from the beginning), lines 38-41 perform acceptance of the new chromosome to the new child population, and a counter is increased for the next generation process.

The next section reports the experiment results and discusses key findings from the running of the algorithm.

\section{Results and discussions}

The results of linear programming optimisation are reported in Table 4. Table 4 shows that the collaborative joint-routing results in lower total cost compared to the total cost if the carriers work independently. Another observable point is the comparison of the minimisation results of each objective separately under collaboration, or the comparison of the two extreme Pareto points. When only the total cost is minimised, the deviation is not concurrently minimised, and the routing suggests that Carrier B is forced to use two of its most expensive vessels (those with the highest capacity). On the other hand, when only the deviation is minimised, even near to non-existent, the total cost shoots up as both carriers are scheduled to route all their vessels. This suggests a conflicting nature between the two objectives, and other non-dominated alternative solutions are worth exploring using the algorithm developed in the previous section.

Various scenarios involving different dispersal mechanisms and controlled parameters are tested. Three dispersal mechanisms are used and named DV(1), DL $(+)$, and DL(-). The DV(1) mechanism uses a dispersal value of 1 and run for 50 generations. The DL-based mechanisms use increasing (or decreasing) distance limits from 1 to 3 (or 3 to 1 ), equally spread on 50 generations. 
Table 4 Results of linear programming optimisation

\begin{tabular}{|c|c|c|c|}
\hline \multicolumn{4}{|c|}{ Per-carrier optimisation } \\
\hline Carrier A: & Minimise cost & Carrier B: & Minimise cost \\
\hline Cost: & $\$ 589,605.50$ & Cost: & $\$ 304,554.90$ \\
\hline Total Cost & $\$ 894,160.40$ & & \\
\hline Routing: & & \multicolumn{2}{|l|}{ Routing: } \\
\hline A1: Sby $\rightarrow$ & $\rightarrow$ Sby & \multicolumn{2}{|c|}{$\mathrm{B} 1: \mathrm{Sby} \rightarrow \mathrm{Jk} 2 / \mathrm{Jk} 1 \rightarrow$ Sby } \\
\hline $\mathrm{A} 2: \mathrm{Sby} \rightarrow$ & Sby & \multicolumn{2}{|c|}{ B2: Sby $\rightarrow$ Bpn $\rightarrow$ Smr $\rightarrow$ Bit $\rightarrow$ Sby } \\
\hline $\mathrm{A} 2: \mathrm{Sby} \rightarrow$ & $\rightarrow$ Sby & \multicolumn{2}{|c|}{ B3: Sby $\rightarrow$ Bjm $\rightarrow$ Mks $\rightarrow$ Sby } \\
\hline \multicolumn{4}{|c|}{$\mathrm{A} 3: \mathrm{Sby} \rightarrow \mathrm{Bjm} \rightarrow \mathrm{Ptk} \rightarrow$ Sby } \\
\hline \multicolumn{4}{|c|}{$\mathrm{A} 3: \mathrm{Sby} \rightarrow \mathrm{Mks} \rightarrow \mathrm{Kdi} \rightarrow \mathrm{Amb} \rightarrow \mathrm{Sby}$} \\
\hline \multicolumn{4}{|c|}{$\mathrm{A} 4: \mathrm{Sby} \rightarrow \mathrm{Jk} 2 / \mathrm{Jk} 1 \rightarrow \mathrm{Sby}$} \\
\hline \multicolumn{4}{|c|}{ Both-carriers optimisation } \\
\hline \multicolumn{2}{|c|}{ Minimise cost } & \multicolumn{2}{|c|}{ Minimise deviation } \\
\hline Cost: & $\$ 548,692.44$ & Cost: & $\$ 891,170.59$ \\
\hline Deviation: & $\$ 83,568.52$ & Deviation: & $\$ 0.04$ \\
\hline \multicolumn{2}{|l|}{ Routing: } & \multicolumn{2}{|l|}{ Routing: } \\
\hline \multicolumn{2}{|l|}{ A1: - } & \multicolumn{2}{|c|}{ A1: Sby $\rightarrow$ Tar $\rightarrow$ Sby } \\
\hline \multicolumn{2}{|l|}{ A2:- } & \multicolumn{2}{|c|}{ A2: Sby $\rightarrow$ Ptk $\rightarrow$ Mdn $\rightarrow$ Sby } \\
\hline \multicolumn{2}{|l|}{ A2:- } & \multicolumn{2}{|c|}{$\mathrm{A} 2:$ Sby $\rightarrow$ Btm $\rightarrow$ Sby } \\
\hline \multicolumn{2}{|c|}{$\mathrm{A} 3: \mathrm{Sby} \rightarrow \mathrm{Bjm} \rightarrow \mathrm{Mks} \rightarrow \mathrm{Bit} \rightarrow$ Sby } & \multicolumn{2}{|c|}{ A3: Sby $\rightarrow$ Amb $\rightarrow$ Sby } \\
\hline \multicolumn{2}{|c|}{$\mathrm{A} 3: \mathrm{Sby} \rightarrow \mathrm{Bpn} \rightarrow \mathrm{Smr} \rightarrow \mathrm{Tar} \rightarrow \mathrm{Sby}$} & \multicolumn{2}{|c|}{$\mathrm{A} 3: \mathrm{Sby} \rightarrow \mathrm{Bjm} \rightarrow \mathrm{Bpn} \rightarrow \mathrm{Bit} \rightarrow$ Sby } \\
\hline \multicolumn{2}{|c|}{$\mathrm{A} 4: \mathrm{Sby} \rightarrow \mathrm{Kdi} \rightarrow \mathrm{Amb} \rightarrow$ Sby } & \multicolumn{2}{|c|}{$\mathrm{A} 4: \mathrm{Sby} \rightarrow \mathrm{Jk} 2 \rightarrow$ Sby } \\
\hline \multicolumn{2}{|l|}{ B1:- } & \multicolumn{2}{|c|}{$\mathrm{B} 1:$ Sby $\rightarrow \mathrm{Smr} \rightarrow$ Sby } \\
\hline \multicolumn{2}{|c|}{ B2: Sby $\rightarrow \mathrm{Jk} 1 \rightarrow$ Ptk $\rightarrow$ Sby } & \multicolumn{2}{|c|}{ B2: Sby $\rightarrow$ Mks $\rightarrow \mathrm{Kdi} \rightarrow$ Sby } \\
\hline \multicolumn{2}{|c|}{ B3: Sby $\rightarrow \mathrm{Jk} 2 \rightarrow \mathrm{Btm} \rightarrow \mathrm{Mdn} \rightarrow$ Sby } & \multicolumn{2}{|c|}{ B3: Sby $\rightarrow$ Jk $1 \rightarrow$ Sby } \\
\hline \multicolumn{2}{|c|}{$T C_{A}=324,010.70$} & \multicolumn{2}{|c|}{$T C_{A}=594,113.75$} \\
\hline$\delta_{A}=-41,78$ & & $\delta_{A}=0.02$ & \\
\hline$T C_{B}=224$ & & $T C_{B}=297$ & \\
\hline$\delta_{B}=41,784$ & & $\delta_{B}=-0.02$ & \\
\hline
\end{tabular}

Prins $(2004,2009)$ proposed an aggressive set of parameters, i.e., higher mutation rate $(10 \%-50 \%)$ and small population size (30-50), leading to fast convergence. In our study here, we are interested to test a smaller mutation rate of $5 \%$ in addition to the suggested aggressive $20 \%$. Mutation rates beyond these figures have also been tested, but a higher rate leads to a poor convergence whereas a lower rate dampens the search speed. The running times of around six hours are still acceptable given the strategic level of planning where the results can be used for a period of several months.

The population size is set at 100 . Smaller population size does not work in this case since instead of finding one best solution, the objective is to find a set of non-dominated solutions. The randomisation effects in the chromosome construction are controlled with the 'rng' function in Matlab so the results from different scenarios are comparable. The 
ray heuristic results in the following order of ports: Sby-Jk1-Jk2-Mdn-Btm-Ptk-BjmBpn-Smr-Tar-Mks-Kdi-Bit-Amb. Table 5 details the final solutions found in different scenarios.

Table 5 listed the Pareto members found in six scenarios. The bolded solutions are unique solutions within a scenario that are not found in the other scenarios. The italicised solutions are untrue Pareto, i.e., they are non-dominated only within a scenario where they reside but if all solutions are combined, they become dominated. For example, solution $890,079 / 1.25$ is non-dominated in $\mathrm{DV}(1) ; p_{m}=0.20$, but dominated by $881,273 / 0.11$ in DL $(+) ; p_{m}=0.20$. Known-not-found (KNF) solutions are the Pareto points not found in one scenario. For example, in $\mathrm{DL}(-) ; p_{m}=0.20$, the four $\mathrm{KNF}$ solutions are the unique solutions in the other mechanisms.

Table 5 Final solutions from various scenarios

\begin{tabular}{|c|c|c|c|c|c|}
\hline \multicolumn{3}{|c|}{$D V(1) ; p_{m}=0.05$} & \multicolumn{3}{|c|}{$D V(1) ; p_{m}=0.20$} \\
\hline No. & Cost & Devn. & No. & Cost & Devn. \\
\hline 1 & $548,692.44$ & $83,568.52$ & 1 & $548,692.44$ & $83,568.52$ \\
\hline 2 & $607,837.82$ & 729.35 & 2 & $600,788.37$ & $10,128.61$ \\
\hline 3 & $622,997.69$ & 393.77 & 3 & $607,837.82$ & 729.35 \\
\hline 4 & $695,639.25$ & 16.44 & 4 & $622,997.69$ & 393.77 \\
\hline 5 & $\mathbf{8 7 7 , 8 2 8 . 0 8}$ & 1.33 & 5 & $872,653.77$ & 104.74 \\
\hline 6 & $885,871.69$ & 0.82 & 6 & $872,761.33$ & 33.03 \\
\hline \multirow[t]{7}{*}{7} & $891,170.59$ & 0.04 & 7 & $871,781.90$ & 32.11 \\
\hline & & & 8 & $877,835.85$ & 3.85 \\
\hline & & & 9 & $879,423.07$ & 3.26 \\
\hline & & & 10 & $881,439.11$ & 1.91 \\
\hline & & & 11 & $881,794.96$ & 1.32 \\
\hline & & & 12 & $890,078.82$ & 1.25 \\
\hline & & & 13 & $891,170.59$ & 0.04 \\
\hline \multicolumn{2}{|c|}{ Unique: 2} & & \multicolumn{3}{|c|}{ Unique: 0} \\
\hline \multicolumn{2}{|c|}{ Untrue: 1} & & \multicolumn{3}{|c|}{ Untrue: 8} \\
\hline \multicolumn{2}{|c|}{ KNF: 6} & & \multicolumn{3}{|c|}{ KNF: 7} \\
\hline \multicolumn{3}{|c|}{ Inf. split.: 1,730} & \multicolumn{3}{|c|}{ Inf. split.: 1,589} \\
\hline \multicolumn{3}{|c|}{ Runtime: 5.06 hrs. } & \multicolumn{3}{|c|}{ Runtime: $5.07 \mathrm{hrs}$. } \\
\hline \multicolumn{3}{|c|}{$D L(+) ; p_{m}=0.05$} & \multicolumn{3}{|c|}{$D L(+) ; p_{m}=0.20$} \\
\hline No. & Cost & Devn. & No. & Cost & Devn. \\
\hline 1 & $548,692.44$ & $83,568.52$ & 1 & $548,692.44$ & $83,568.52$ \\
\hline 2 & $600,788.37$ & $10,128.61$ & 2 & $606,035.08$ & $22,495.61$ \\
\hline 3 & $607,837.82$ & 729.35 & 3 & $607,837.82$ & 729.35 \\
\hline 4 & $622,997.69$ & 393.77 & 4 & $622,997.69$ & 393.77 \\
\hline 5 & $629,684.60$ & 358.44 & 5 & $870,955.68$ & 25.30 \\
\hline 6 & $872,613.36$ & 131.68 & 6 & $873,754.08$ & 17.49 \\
\hline 7 & $872,653.77$ & 104.74 & 7 & $878,709.61$ & 11.99 \\
\hline
\end{tabular}


Table 5 Final solutions from various scenarios (continued)

\begin{tabular}{|c|c|c|c|c|c|}
\hline \multicolumn{3}{|c|}{$D L(+) ; p_{m}=0.05$} & \multicolumn{3}{|c|}{$D L(+) ; p_{m}=0.20$} \\
\hline No. & Cost & Devn. & No. & Cost & Devn. \\
\hline 8 & $872,658.85$ & 101.36 & 8 & $878,719.60$ & 4.26 \\
\hline 9 & $872,761.33$ & 33.03 & 9 & $879,261.52$ & 2.91 \\
\hline 10 & $874,082.54$ & 28.60 & 10 & $881,273.35$ & 0.11 \\
\hline 11 & $876,649.16$ & 12.52 & 11 & $891,170.59$ & 0.04 \\
\hline 12 & $878,793.89$ & 6.90 & & & \\
\hline 13 & $883,899.38$ & 2.24 & & & \\
\hline 14 & $886,973.25$ & 2.04 & & & \\
\hline 15 & $890,655.38$ & 0.68 & & & \\
\hline 16 & $891,170.59$ & 0.04 & & & \\
\hline \multicolumn{2}{|c|}{ Unique: 0} & & \multicolumn{3}{|c|}{ Unique: 1} \\
\hline \multicolumn{2}{|c|}{ Untrue: 10} & & \multicolumn{3}{|c|}{ Untrue: 6} \\
\hline \multicolumn{2}{|c|}{ KNF: 6} & & \multicolumn{3}{|c|}{ KNF: 7} \\
\hline \multicolumn{3}{|c|}{ Inf. split.: 2,149 } & \multicolumn{3}{|c|}{ Inf. split.: 2,184} \\
\hline \multicolumn{3}{|c|}{ Runtime: 6.13 hrs. } & \multicolumn{3}{|c|}{ Runtime: $6.14 \mathrm{hrs}$. } \\
\hline \multicolumn{3}{|c|}{$D L(-) ; p_{m}=0.05$} & \multicolumn{3}{|c|}{$D L(-) ; p_{m}=0.20$} \\
\hline No. & Cost & Devn. & No. & Cost & Devn. \\
\hline 1 & $548,692.44$ & $83,568.52$ & 1 & $548,692.44$ & $83,568.52$ \\
\hline 2 & $600,788.37$ & $10,128.61$ & 2 & $600,788.37$ & $10,128.61$ \\
\hline 3 & $877,832.28$ & 1.47 & 3 & $607,837.82$ & 729.35 \\
\hline 4 & $878,475.54$ & 0.18 & 4 & $622,997.69$ & 393.77 \\
\hline \multirow[t]{6}{*}{5} & $891,170.59$ & 0.04 & 5 & $629,684.60$ & 358.44 \\
\hline & & & 6 & $873,730.58$ & 1.82 \\
\hline & & & 7 & $874,042.13$ & 1.66 \\
\hline & & & 8 & $877,832.28$ & 1.47 \\
\hline & & & 9 & $881,074.66$ & 0.45 \\
\hline & & & 10 & $891,170.59$ & 0.04 \\
\hline \multicolumn{3}{|c|}{ Unique: 1} & \multicolumn{3}{|c|}{ Unique: 2} \\
\hline \multicolumn{3}{|c|}{ Untrue: 1} & \multicolumn{3}{|c|}{ Untrue: 2} \\
\hline \multicolumn{3}{|c|}{ KNF: 9} & \multicolumn{3}{|c|}{ KNF: 4} \\
\hline \multicolumn{3}{|c|}{ Inf. split.: 1,938} & \multicolumn{3}{|c|}{ Inf. split.: 2,353} \\
\hline \multicolumn{3}{|c|}{ Runtime: 5.88 hrs. } & \multicolumn{3}{|c|}{ Runtime: 5.99 hrs. } \\
\hline
\end{tabular}

Notes: 1 bold: unique solutions

2 italic: solutions non-dominated within scenario

$3 \mathrm{KNF}=$ known not found. 
Figure 7 Scatter plots of population (see online version for colours)
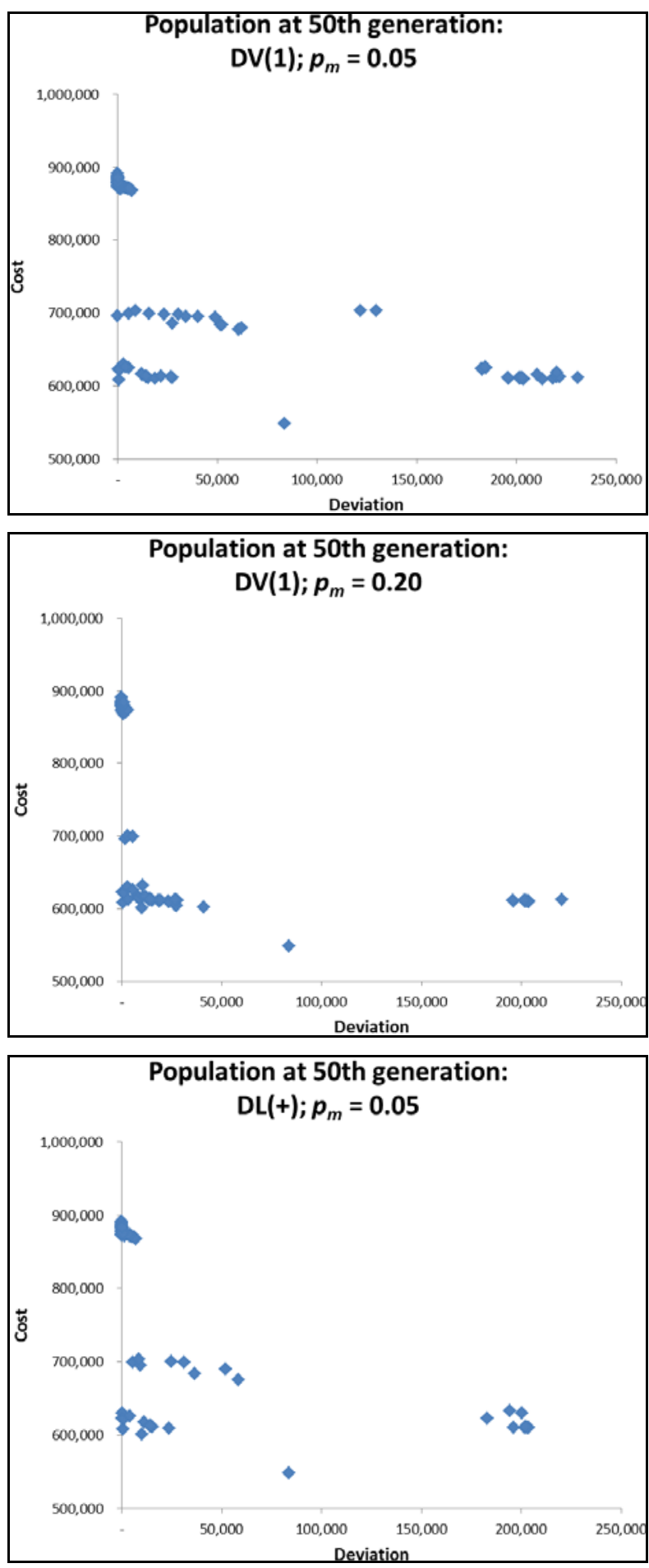
Figure 7 Scatter plots of population (continued) (see online version for colours)

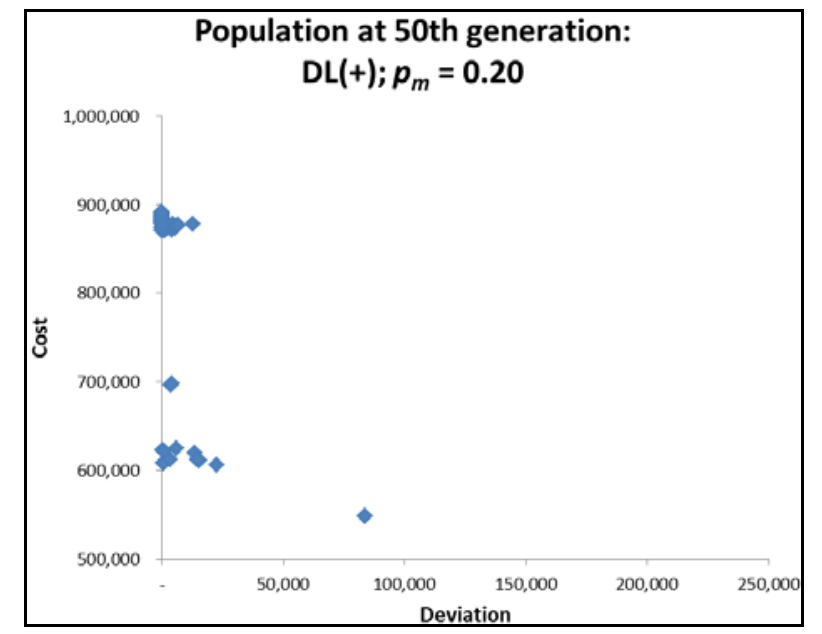

The combination of the numbers of unique, untrue Pareto, and the KNF solutions determines the strength of a mechanism in a multi-objective experiment. Higher number of unique solutions and fewer untrue Pareto and KNF solutions are the criteria sought by a robust mechanism. In this particular case, the performance of a mechanism depends on the scenario parameters and no single mechanism shows superiority to the rest. More specifically, DV(1) works better with smaller mutation rate, DL(-) favours more aggressive rate, but $\mathrm{DL}(+)$ does not show a clear preference. Running times are higher with pm 0.20 , which is natural since mutation is triggered more often leading to faster convergence. This is shown in Figure 7 where the solutions in the right-hand plots are more concentrated in the bottom-left area of the feasible space (the supposed Pareto front for a min-min problem), whereas the left-hand plots exhibit solutions that are still 'inside' the feasible region. In general with the computation time, the DV(1) mechanism is more efficient than the DL mechanisms. Part of the long running times are suspected due to the inherent complexity of the problem that weighs the efficiency of Split.

Finally, two non-dominated routing solutions with reasonable costs (below $\$ 700,000$ ) and not too extreme deviations are provided in Table 6 as examples and the first solution is visualised in Figure 8. It is obvious that the number of routes in the obtained solutions is fewer than that in the per-carrier optimisation listed in Table 4. Moreover, with total costs not too far away from the minimum-cost solution in Table 4, these can be considered acceptable for both carriers. Carrier B can now use its smallest vessel B1 instead of being forced to use both of its two expensive vessels, B2 and B3. Note that, initially, in the minimum-cost solution, Carrier B is the 'losing' party because its total cost is $\$ 41,784$ larger than its targeted proportionate cost, whereas Carrier A benefits from the partnership by a saving of that amount (see Table 4). In the two solutions in Table 6, it is now Carrier B that gets the benefit at the expense of Carrier A, however, the discrepancy of $\$ 5,064$ or $\$ 365$ is much lower than that in the minimum-cost solution. 
Table 6 Two non-dominated routing solutions

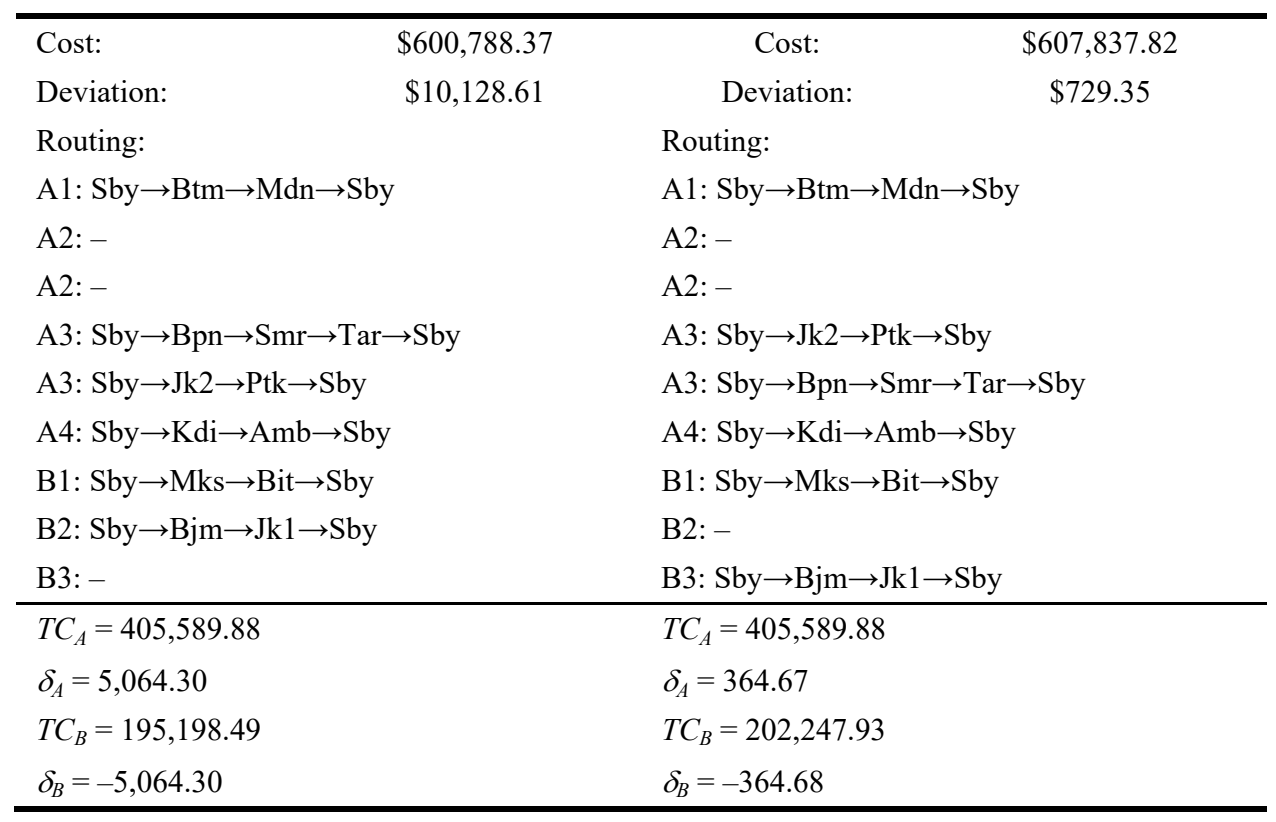

Figure 8 Routing visualisation of solutions (see online version for colours)

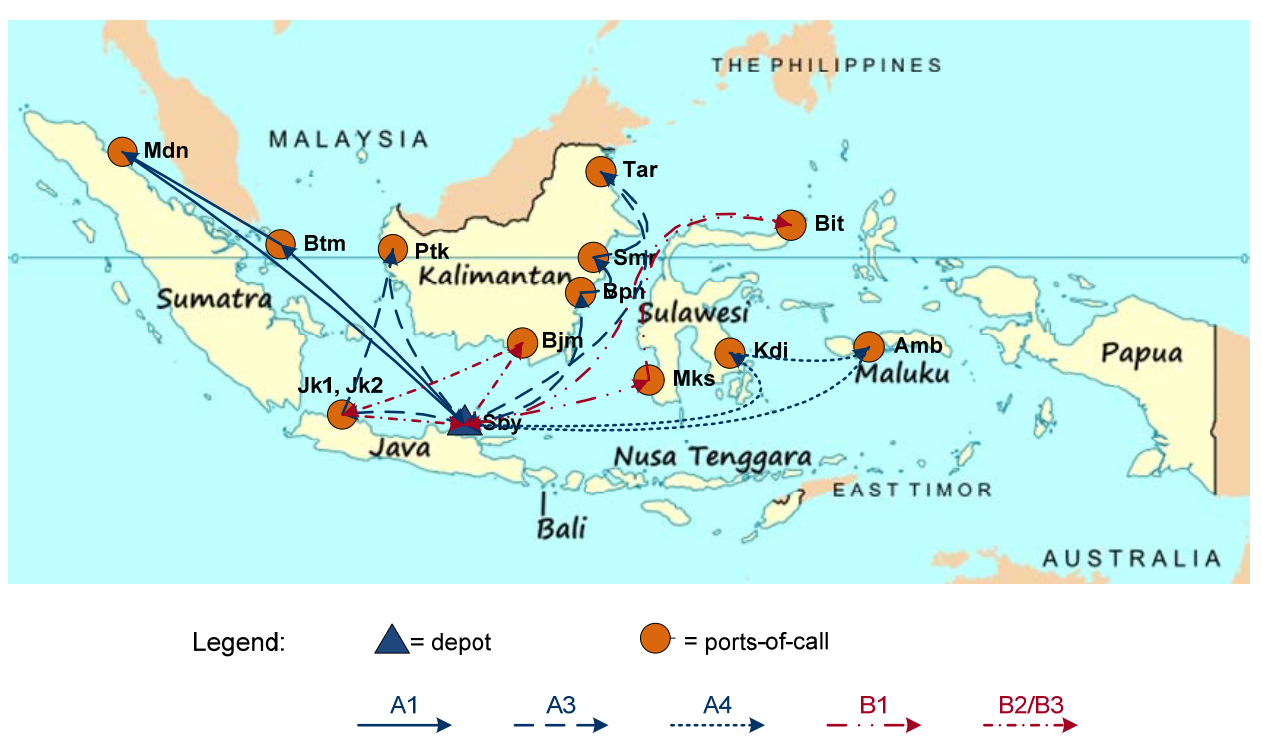

\section{Conclusions and further remarks}

In this paper, we propose a new method to solve a multi-objective problem in maritime logistics collaboration of two liner shipping companies in the scope of joint-routing network design. The ship routing problem is formulated with two objectives: 
minimisation of total cost and minimisation of deviation in fair cost proportion. An MOEA method NSGA-II and the tenets of effective genetic algorithms from the published literature are used to build the proposed algorithm. The algorithm is tested on data generated from the Indonesian archipelago. Neither our method nor an example of its application in a real-life problem has ever been documented in the literature, therefore this research bears high practical values and significant contribution in this domain.

The first step taken is to prove the benefit of collaboration with regard to the total costs. The total cost of which carriers work independently and that of collaboration in capacity sharing are compared, and the optimisation results show that the collaboration alternative leads to a lower total cost. However, it is realised that the obtained minimum cost does not satisfy the interests of both carriers; in this case, Carrier B is forced to use its expensive vessels. The second objective is introduced to avoid this problem by regulating so that the cost proportion is closed to the proportion of fleet contribution, thus serves as a balancing factor in the collaboration efforts. Our algorithm is built to solve this problem by finding a number of solutions that does not sacrifice too much either of the carriers.

Three dispersal mechanisms are tested with two different mutation probabilities and the experiment results show that different probability supports different mechanism, except for $\mathrm{DL}(+)$ that indicates no preference. Specifically, mutation rate 0.05 works well with DV(1), whereas mutation rate 0.20 is better with DL(-). In all scenarios, running times are higher in mutation rate 0.20 , and in general the DV(1) mechanism is faster than both DL mechanisms. Finally, examples of non-dominated solutions found by the algorithm are translated as the joint-routing of both carriers to indicate the practical outcomes of this research.

Expensive computation time is noted as an area that deserves further improvement. The algorithm is coded and run on Matlab and a switch to a more efficient programming language such as Java could remedy the situation. In addition to that technical factor, improvement in the algorithm could also be pursued with attention given to improving the Split procedure and reducing the amount of infeasible splitting in the chromosome construction phase. Furthermore, different crossover operators from the OX used in the algorithm are also worth exploring for a possibility for a more efficient algorithm.

\section{Acknowledgements}

The authors would like to thank the anonymous referees for their valuable inputs and suggestions that improve the presentation of this paper.

\section{References}

Agarwal, R. and Ergun, Ö. (2010) 'Network design and allocation mechanisms for carrier alliances in liner shipping', Operations Research, Vol. 58, No. 6, pp.1726-1742.

Agra, A., Christiansen, M., Figueiredo, R., Hvattum, L.M., Poss, M. and Requejo, C. (2013) 'The robust vehicle routing problem with time windows', Computers \& Operations Research, Vol. 40, No. 3, pp.856-866.

Álvarez-SanJaime, Ó., Cantos-Sánchez, P., Moner-Colonques, R. and Sempere-Monerris, J.J. (2013) 'Vertical integration and exclusivities in maritime freight transport', Transportation Research E, May, Vol. 51, pp.50-61. 
Archetti, C. and Speranza, M.G. (2012) 'Vehicle routing problems with split deliveries', International Transactions in Operational Research, Vol. 19, Nos. 1-2, pp.3-22.

Asgari, N., Farahani, R.Z. and Goh, M. (2013) 'Network design approach for hub ports-shipping companies competition and cooperation', Transportation Research A, February, Vol. 48, pp.1-18.

Baños, R., Ortega, J., Gil, C., Márquez, A.L. and De Toro, F. (2013) 'A hybrid meta-heuristic for multi-objective vehicle routing problems with time windows', Computers \& Industrial Engineering, Vol. 65, No. 2, pp.286-296.

Boros, E., Lei, L., Zhao, Y. and Zhong, H. (2008) 'Scheduling vessels and container-yard operations with conflicting objectives', Annals of Operations Research, Vol. 161, No. 1, pp.149-170.

Bräysy, O., Dullaert, W. and Gendreau, M. (2005) 'Evolutionary algorithm for the vehicle routing problem with time windows', Journal of Heuristics, Vol. 10, No. 6, pp.587-611.

Cordeau, J-F., Laporte, G., Savelsbergh, M.W.P. and Vigo, D. (2007) 'Vehicle routing', in Barnhart, C. and Laporte, G. (Eds.): Handbook in $O R \& M S$, No. 14, pp. 367-428, Elsevier, Amsterdam.

Dantzig, G.B. and Ramser, J.H. (1959) 'The truck dispatching problem', Management Science, Vol. 6, No. 1, pp.80-91.

Deb, K., Agrawa, S., Pratap, A. and Meyarivan, T. (2000) 'A fast elitist non-dominated sorting genetic algorithm for multi-objective optimization: NSGA-II', in Proceedings of the Parallel Problem Solving from Nature VI (PPSN-VI), pp. 849-858.

Ding, J-F. and Liang, G-S (2005) 'Using fuzzy MCDM to select partners of strategic alliances for liner shipping', Information Sciences, Vol. 173, Nos. 1-3, pp.197-225.

Edisiringhe, L., Wijeratne, A.W. and Zhihong, J. (2015) 'Evaluation of expected payoff through container interchange between shipping lines: a solution to container inventory imbalance in Sri Lanka', International Journal of Logistics and Systems Management, Vol. 21, No. 4, pp.503-533.

Eksioglu, B., Vural, A.V. and Reisman, A. (2009) 'The vehicle routing problem: a taxonomic review', Computers \& Industrial Engineering, Vol. 57, No. 4, pp.1472-1483.

El-Sherbeny, N.A. (2010) 'Vehicle routing with time windows: an overview of exact, heuristic and metaheuristic methods', Journal of King Saud University, Vol. 22, No. 3, pp.123-131.

Gambardella, L.M., Taillard, E. and Agazzi, G. (1999) 'MACS-VRPTW: a multiple ant colony system for vehicle routing problems with time windows', in Corne, D., Dorigo, M. and Glover, F. (Eds.): New Ideas in Optimization, pp.63-76, McGraw-Hill, London.

Gendreau, M., Laporte, G. and Potvin, J-Y. (2002) 'Metaheuristics for the capacitated VRP', in Toth, P. and Vigo, D. (Eds.): The Vehicle Routing Problem, SIAM Monographs on Discrete Mathematics and Application, pp.129-154, Society for Industrial and Applied Mathematics, Philadelphia.

Gendreau, M., Potvin, J-Y., Bräysy, O., Hasle, G. and Løkketangen, A. (2008) 'Metaheuristics for the vehicle routing problem and its extensions: a categorized bibliography', in Golden, B., Raghavan, S. and Wasil, E. (Eds.): The Vehicle Routing Problem: Latest Advances and New Challenges, pp.143-169, Springer, New York.

Hsu, C-I. and Hsieh, Y-P. (2007) 'Routing, ship size, and sailing frequency decision-making for a maritime hub-and-spoke container network', Mathematical and Computer Modelling, Vol. 45, Nos. 7-8, pp.899-916.

Imran, A., Salhi, S. and Wassan, N.A. (2009) 'A variable neighborhood-based heuristic for the heterogeneous fleet vehicle routing problem', European Journal of Operational Research, Vol. 197, No. 2, pp.509-518.

Josefowiez, N., Semet, F. and Talbi, E-G. (2008a) 'From single-objective to multi-objective vehicle routing problems: motivations, case studies, and methods', in Golden, B., Raghavan, S. and Wasil, E. (Eds.): The Vehicle Routing Problem: Latest Advances and New Challenges, pp.445-471, Springer, New York. 
Josefowiez, N., Semet, F. and Talbi, E-G. (2008b) 'Multi-objective vehicle routing problems', European Journal of Operational Research, Vol. 189, No. 2, pp.293-309.

Karlaftis, M.G., Kepaptsoglou, K. and Sambracos, E. (2009) 'Containership routing with time deadlines and simultaneous deliveries and pick-ups', Transportation Research E, Vol. 45, No. 1, pp.210-221.

Lei, L., Fan, C., Boile, M. and Theofanis, S. (2008) 'Collaborative vs. non-collaborative container-vessel scheduling', Transportation Research E, Vol. 44, No. 3, pp.504-520.

Lin, C., Choy, K.L., Ho, G.T.S., Chung, S.H. and Lam, H.Y. (2013) 'Survey of green vehicle routing problem: past and future trends', Expert Systems with Applications, Vol. 1, No. 4, pp.1118-1138.

Melián-Batista, B., De Santiago, A., AngelBello, F. and Alvarez, A. (2014) 'A bi-objective vehicle routing problem with time windows: a real case in Tenerife', Applied Soft Computing, April, Vol. 17, pp.140-152.

OECD (2012) 'Indonesia: regulatory and competition issues in ports, rail, and shipping', OECD Reviews of Regulatory Reform, pp.6-23.

Ombuki, B., Ross, B.J. and Hanshar, F. (2006) 'Multi-objective genetic algorithms for vehicle routing problem with time windows', Applied Intelligence, Vol. 24, No. 1, pp.17-30.

Panayides, P.M. and Wiedmer, R. (2011) 'Strategic alliances in container liner shipping', Research in Transportation Economics, Vol. 32, No. 1, pp.25-38.

Prins, C. (2004) 'A simple and effective evolutionary algorithm for the vehicle routing problem', Computers \& Operations Research, Vol. 31, No. 12, pp.1985-2002.

Prins, C. (2009) 'Two memetic algorithms for heterogeneous fleet vehicle routing problems', Engineering Applications of Artificial Intelligence, Vol. 22, No. 6, pp.916-928.

Romero, G., Dur'an, G., Marenco, J. and Weintraub, A. (2013) 'An approach for efficient ship routing', International Transactions in Operational Research, Vol. 20, No. 6, pp.767-794.

Sambracos, E., Paravantis, J.A., Tarantilis, C.D. and Kiranoudis, C.D. (2004) 'Dispatching of small containers via coastal freight liners: the case of the Aegean Sea', European Journal of Operational Research, Vol. 152, No. 2, pp.365-381.

Silva Jr., O.S. and Leal, J.E. (2011) 'An efficient ant colony system for vehicle routing problems with time windows', International Journal of Logistics and Systems Management, Vol. 10, No. 2, pp.224-240.

Singapore Logistics Association (2010) The Practitioner's Definitive Guide Seafreight Forwarding, 3rd ed., Straits Times Press, Singapore.

Srinivas, N. and Deb, K. (1994) 'Multi-objective function optimization using non-dominated sorting genetic algorithms', Evolutionary Computation Journal, Vol. 2, No. 3, pp.221-248.

Stopford, M. (2009) Maritime Economics, 3rd ed., Routledge, Abingdon.

Takano, K. and Arai, M. (2009) 'A genetic algorithm for the hub-and-spoke problem applied to containerized cargo transport', Journal of Marine Science and Technology, Vol. 14, No. 2, pp.256-274.

UNCTAD (2010) Review of Maritime Transport.

UNCTAD (2011) Review of Maritime Transport.

UNCTAD (2012) Review of Maritime Transport.

UNCTAD (2014) Review of Maritime Transport.

Vidal, T., Crainic, T.G., Gendreau, M. and Prins, C. (2013) 'Heuristics for multi-attribute vehicle routing problems: a survey and synthesis', European Journal of Operational Research, Vol. 231, No. 1, pp.1-21.

Wibisono, E. and Jittamai, P. (2015) 'Collaborative capacity sharing in liner shipping operations', International Journal of Logistics Systems and Management, Vol. 22, No. 4, pp.520-539.

World Shipping Council (2014) [online] http://www.worldshipping.org/. 
Yang, D., Liu, M. and Shi, X. (2011) 'Verifying liner shipping alliance's stability by applying core theory', Research in Transportation Economics, Vol. 32, No. 1, pp.15-24.

Zitzler, E., Laumanns, M. and Bleuler, S. (2003) 'A tutorial on evolutionary multiobjective optimization', in Gandibleux, X., Sevaux, M., Sörensen, K. and T'kindt, V. (Eds.): Lecture Notes in Economics and Mathematical Systems, pp.3-38, Springer, Berlin. 